\title{
Chemokine CCL2-CCR2 Signaling Induces Neuronal Cell Death via STAT3 Activation and IL-1 $\beta$ Production after Status Epilepticus
}

\author{
Dai-Shi Tian, ${ }^{1,3 *}$ - Jiyun Peng, ${ }^{3,4 *}$ ๑Madhuvika Murugan, ${ }^{3,4}$ Li-Jie Feng, ${ }^{3}$ Jun-Li Liu, ${ }^{2,3}$ @Ukpong B. Eyo, ${ }^{3,4}$ \\ ๑Li-Jun Zhou, ${ }^{3}{ }^{\circledR}$ Rochelle Mogilevsky, ${ }^{3}$ Wei Wang, ${ }^{1}$ and $\odot$ Long-Jun Wu ${ }^{3,4}$ \\ ${ }^{1}$ Department of Neurology, Tongji Hospital, and ${ }^{2}$ Cancer Center, Union Hospital, Tongji Medical College, Huazhong University of Science and Technology, \\ Wuhan 430022, China, ${ }^{3}$ Department of Cell Biology and Neuroscience, School of Arts and Sciences, Rutgers University, Piscataway, New Jersey 08854, and \\ ${ }^{4}$ Department of Neurology, Mayo Clinic, Rochester, Minnesota 55905
}

Elevated levels of chemokine C-C motif ligand 2 (CCL2) and its receptor CCR2 have been reported in patients with temporal lobe epilepsy and in experimental seizures. However, the functional significance and molecular mechanism underlying CCL2-CCR2 signaling in epileptic brain remains largely unknown. In this study, we found that the upregulated CCL2 was mainly expressed in hippocampal neurons and activated microglia from mice $1 \mathrm{~d}$ after kainic acid (KA)-induced seizures. Taking advantage of $C X 3 C R 1^{G F P /+}: C C R 2^{R F P /+}$ double-transgenic mice, we demonstrated that CCL2-CCR2 signaling has a role in resident microglial activation and blood-derived monocyte infiltration. Moreover, seizure-induced degeneration of neurons in the hippocampal CA3 region was attenuated in mice lacking CCL2 or CCR2. We further showed that CCR2 activation induced STAT3 (signal transducer and activator of transcription 3) phosphorylation and IL-1 $\beta$ production, which are critical for promoting neuronal cell death after status epilepticus. Consistently, pharmacological inhibition of STAT3 by WP1066 reduced seizure-induced IL-1 $\beta$ production and subsequent neuronal death. Two weeks after KA-induced seizures, CCR2 deficiency not only reduced neuronal loss, but also attenuated seizure-induced behavioral impairments, including anxiety, memory decline, and recurrent seizure severity. Together, we demonstrated that CCL2-CCR2 signaling contributes to neurodegeneration via STAT3 activation and IL-1 $\beta$ production after status epilepticus, providing potential therapeutic targets for the treatment of epilepsy.

Key words: CCL2; epilepsy; MCP-1; microglia; monocytes; neuroinflammation

Significance Statement

Epilepsy is a global concern and epileptic seizures occur in many neurological conditions. Neuroinflammation associated with microglial activation and monocyte infiltration are characteristic of epileptic brains. However, molecular mechanisms underlying neuroinflammation in neuronal death following epilepsy remain to be elucidated. Here we demonstrate that CCL2-CCR2 signaling is required for monocyte infiltration, which in turn contributes to kainic acid (KA)-induced neuronal cell death. The downstream of CCR2 activation involves STAT3 (signal transducer and activator of transcription 3) phosphorylation and IL-1 $\beta$ production. Two weeks after KA-induced seizures, CCR2 deficiency not only reduced neuronal loss, but also attenuated seizure-induced behavioral impairments, including anxiety, memory decline, and recurrent seizure severity. The current study provides a novel insight on the function and mechanisms of CCL2-CCR2 signaling in KA-induced neurodegeneration and behavioral deficits.

\section{Introduction}

Epilepsy is a global concern with an estimated 50-65 million living with the condition worldwide (Thurman et al., 2011; Vez-
Received Feb. 2, 2017; revised June 20, 2017; accepted July 12, 2017.

Author contributions: D.-S.T., J.P., W.W., and L.-J.W. designed research; D.-S.T., J.P., M.M., L.-J.F., J.-L.L., U.B.E., L.-J.Z., and R.M. performed research; D.-S.T., J.P., M.M., L.-J.F., and J.-L.L. analyzed data; D.-S.T., J.P., M.M., U.B.E., W.W., and L.J.W. wrote the paper.

This work was supported by National Institutes of Health (R01NS088627, R21DE025689), the New Jersey Commission on Spinal Cord Research (CSCR15ERG015), the National Natural Science Foundation of China (81101766, zani et al., 2011), causing sufferers to die on average 2-10 years sooner than other people (Gaitatzis et al., 2004). The disorder is

81571132, 61327902), and the National Basic Research Development Program (973 Program) of China (2011CB504403). We thank Dr. Richard Ransohoff (Biogen) for critical reading of the manuscript.

The authors declare no competing financial interests.

*D.-S.T and J.P. contributed equally to this work.

Correspondence should be addressed to either of the following: Dr. Wei Wang, Department of Neurology, Tongji Hospital, Tongji Medical College, Huazhong University of Science and Technology, Wuhan 430030, China. E-mail: wwang@vip.126.com; or Dr. Long-Jun Wu, Department of Neurology, Mayo Clinic, 200 First Street SW, Rochester, MN 55905. E-mail:wu.longjun@mayo.edu. 
characterized by increased occurrence of seizures resulting from excessive or uncontrolled increase in neuronal activity (Fisher et al., 2005). Epileptic seizures are known to occur in many neurological conditions, including as a consequence of stroke and traumatic brain injury (Vezzani et al., 1999; Temkin, 2009). Current antiepileptic strategies primarily target neuronal mechanisms. These medical therapies have proven insufficient in at least a third of patients with recurrent seizures, raising the need for alternative and/or complementary strategies (Devinsky et al., 2013). Aside from neuronal hyperactivity, characteristics of epileptic brains include neuroinflammation associated with activation of resident microglia and infiltration of peripheral monocytes (Shapiro et al., 2008). Indeed, autopsy analysis of human patients with intractable seizures revealed an 11-fold increase in microglia/macrophage reactivity in the hippocampus of epileptic brains (Beach et al., 1995).

Although there is a strong correlation between the severity of epilepsy and degree of microglial/macrophage accumulation (Boer et al., 2006), the morphological and proliferative signs of their activation are generally delayed (Avignone et al., 2008; Drexel et al., 2012; Eyo et al., 2017). Therefore, it is still unclear whether microglia/macrophage activation is a secondary reaction to neuronal injury following the primary seizure or is actively involved in epileptogenesis. Interestingly, both beneficial and detrimental roles have been attributed to microglia/macrophages in epilepsy. For example, recent studies suggest a neuroprotective role of microglia in epilepsy by a microglial ablation strategy as well the use of $P 2 Y 12$ knock-out $\left(P 2 Y_{12}{ }^{-/}\right)$mice (Mirrione et al., 2010; Eyo and Wu, 2013; Eyo et al., 2014, 2016). On the other hand, reactive microglia/macrophages are known to release a variety of proinflammatory mediators that aggravate seizure activities and excitotoxicity under epileptic conditions (Ding et al., 2014; Miskin and Hasbani, 2014). Indeed, broad microglial inhibitors, such as minocycline and macrophage inhibitory factor (MIF), reduce neurodegeneration following epilepsy (Rogove and Tsirka, 1998; Wang et al., 2012). However, the molecular mechanism underlying microglia/macrophage-induced neuronal cell death following epilepsy remains to be elucidated.

Chemokines are proinflammatory mediators critical in recruiting leukocytes into the brain following seizures. Recent studies have shown the upregulation of several chemokines, including chemokine $\mathrm{C}$-C motif ligand 2 (CCL2), in patients with temporal lobe epilepsy and in rodents after experimental seizures (Manley et al., 2007; Wu et al., 2008). CCL2 is a potent chemoattractant protein for monocytes, and hence is alternatively referred to as monocyte chemoattractant protein-1 (MCP-1). Elevated levels of CCL2 expression in an inflamed brain were associated with activation and recruitment of macrophages/microglia to the injury sites (Selenica et al., 2013). CCL2 attracts and acts via chemokine $\mathrm{C}-\mathrm{C}$ motif receptor 2 (CCR2)-expressing cells, thereby regulating migration and infiltration of monocytes, T-lymphocytes, and natural killer cells to regions of inflammation (Rollins, 1991; Semple et al., 2010). In addition to CCL2 upregulation, the expression of CCR2 was also significantly increased in the hippocampus in a rat model of pilocarpine-induced status epilepticus (Foresti et al., 2009). The results obtained in experimental animal models and in human patients point to a key role for CCL2-CCR2 signaling in epilepsy.

Despite the well characterized regulation of CCL2 following epilepsy, the molecular mechanisms underlying the CCL2-CCR2

DOI:10.1523/JNEUROSCI.0315-17.2017

Copyright $\odot 2017$ the authors $\quad 0270-6474 / 17 / 377879-15 \$ 15.00 / 0$ signaling and its functional significance in the pathogenesis of epilepsy remain largely unknown. Here we show direct evidence using the double-transgenic $C X 3 C R 1^{G F P /+}: C C R 2^{R F P /+}$ mice that CCL2-CCR2 signaling is required for macrophage infiltration and neurodegeneration in the hippocampus in a mouse model of kainic acid (KA)-induced status epilepticus. The underlying neurotoxic mechanism of CCL2-CCR2 signaling in activated microglia/macrophages involves the STAT3 (signal transducer and activator of transcription 3 ) pathway and IL- $1 \beta$ production. The current study provides a novel therapeutic strategy targeting CCL2-CCR2 signaling against neuroinflammation and hippocampal neurodegeneration under epileptic conditions.

\section{Materials and Methods}

\section{Animals and seizure models}

Mice were used in accordance with institutional guidelines as approved by the animal care and use committee at Rutgers University. Adult C57BL/6 wild-type (WT) mice, $C C R 2^{R F P / R F P}\left(C C R 2^{-1-}\right)$ mice, $C X 3 C R 1^{G F P / G F P}$ mice, $C X 3 C R 1^{G F P /+}$ mice, $C C L 2^{-/-}$mice were all purchased from Jackson Laboratory. Double-transgenic CCR2 $2^{R F P /+}$ : $C X 3 C R 1^{G F P /+}$ mice were obtained by crossing CCR2 ${ }^{R F P / R F P}$ mice with $C X 3 C R 1^{G F P / G F P}$ mice. For all seizure experiments, 6 -8-week-old mice of both genders were used. All animal procedures performed in this study were in accordance with institutional guidelines, as approved by the animal care and use committee at Rutgers University. The KA-induced seizure models in mice were described in our previous studies (Eyo et al., 2014, 2015). Briefly, animals were anesthetized with isoflurane, stereotaxically implanted with a 26 gauge, stainless steel, guide cannula aimed toward the lateral cerebral ventricle [from bregma: $-0.2 \mathrm{~mm}$ anteroposterior (AP), $+1.0 \mathrm{~mm}$ mediolateral (ML), $-2.0 \mathrm{~mm}$ dorsoventral (DV)], and then were intracerebroventricularly injected with KA at $0.15 \mu \mathrm{g}$ in 5 $\mu l$ of artificial CSF (aCSF). To study recurrent seizure activity, a second dose of KA $(0.15 \mu \mathrm{g} / 5 \mu \mathrm{l})$ was administered $14 \mathrm{~d}$ after the first dose and the seizure scores were monitored. Sham controls were injected with $5 \mu \mathrm{l}$ of aCSF.

\section{Seizure quantification}

Seizure behavior was monitored under a modified Racine scale as follows (Racine, 1972; Eyo et al., 2014): 1, freezing behavior; 2, rigid posture with raised tail; 3, continuous head bobbing and forepaws shaking; 4, rearing, falling, and jumping; 5, continuous level 4; and 6, loss of posture and generalized convulsion activity. Mice progressed at least to stage 3 and were killed 1 or $3 \mathrm{~d}$ after seizure. For electroencephalographic (EEG) recordings, stainless steel bone-screw recording electrodes (Pinnacle Technologies) were implanted together with the intracerebroventricular guide cannula. Four screws were placed on the dura through burr holes in the skull and electrode leads were attached to a microplug. The intracerebroventricular guide tube was modified to be implanted at $30^{\circ}$ from the vertical angle to avoid the position conflict with the microplug. Dental cement was applied to fix both electrodes and guide cannula in place. Animals were connected to the recording system for baseline recording and habituation to the environment after $1 \mathrm{~d}$ recovery. After $2 \mathrm{~d}$, KA was injected through the guide cannula to induce seizures. Seizure spell was defined as high-frequency, high-voltage synchronized polyspike or paroxysmal sharp waves with amplitude $>2$-fold background and lasting $>6 \mathrm{~s}$. The EEG recordings were made continuously from $1 \mathrm{~d}$ before to $14 \mathrm{~d}$ after intracerebroventricular KA. Seizure spells were not detected in any mice after $2 \mathrm{~h}$ of KA injection.

\section{Behavioral assays}

Open-field test. The open-field test was used to detect seizure-related anxiety-like behavior. Mice received a 5 min session in an empty openfield box equipped with a video camera $(50 \times 50 \mathrm{~cm})$. The overall distance traveled by the mice, the distance from the center, and the time spent in the center of the field were measured to evaluate the anxiety levels. The center region is designated as $25 \times 25 \mathrm{~cm}$ in the open field.

Novel-object recognition. To determine whether seizure-induced neuronal damage impairs hippocampal-dependent cognitive function, the 
novel-object recognition test was used. This test measures recognition memory and is performed as previously described with minor modifications (Matsuda et al., 2015). Briefly, each mouse was subject to a $10 \mathrm{~min}$ acquisition trial, during which the mouse was placed in the open field in the presence of two identical objects A (acquisition task). On completion of $10 \mathrm{~min}$ of exploration, the mouse was returned to its cage for $1 \mathrm{~h}$. The mouse was then placed back in the box and introduced to the familiar object A and a novel object B for another 5 min (test task). The total time spent exploring each of the two objects was recorded. A preference index for novel object used to measure recognition memory is defined as the percentage of time exploring the novel object (B) divided by the total time spent exploring both objects: $[\mathrm{B} /(\mathrm{A}+\mathrm{B})] \times 100$.

\section{Immunohistochemistry}

At 1 and $3 \mathrm{~d}$ after seizures, animals were deeply anesthetized with isoflurane and perfused with PBS, followed by $4 \%$ paraformaldehyde with $0.5 \%$ picric acid. After the perfusion, the brain was removed and postfixed in the same fixative overnight. Brain sections $(15 \mu \mathrm{m})$ were cut in a cryostat and processed for immunofluorescence. All histological data were obtained from sections taken from coronal planes -1.0 to +2.0 $\mathrm{mm} \mathrm{AP}$, and the center of the field of view was focused on the hippocampal CA3 region (+2.3-2.8 mm ML; + 2.5-3.0 mm DV). The sections were first blocked with $5 \%$ goat or donkey serum for $1 \mathrm{~h}$ at room temperature, and then incubated overnight at $4^{\circ} \mathrm{C}$ with the following primary antibodies: Iba- 1 antibody (rabbit, 1:1000; Wako), NeuN antibody (rabbit, 1:500; Abcam), GFAP (rabbit, 1:500; Millipore Bioscience Research Reagents), MCP-1 antibody (mouse, 1:200; Novus Biologicals), RFP (mouse, 1;500; Abcam), Iba-1 antibody (goat, 1:200; Abcam), IL-1 $\beta$ (rabbit, 1:500; Abcam), phosphorylated STAT3 (pSTAT3) or totalSTAT3 (1:200, rabbit; Cell Signaling Technology). The sections were then incubated for $1 \mathrm{~h}$ at room temperature with Cy3-conjugated or FITC-conjugated secondary antibodies (1:500; Jackson ImmunoResearch). For double immunofluorescence, sections were incubated with a mixture of polyclonal and monoclonal primary antibodies, followed by a mixture of FITC-conjugated and Cy3-congugated secondary antibodies. The stained sections were examined and captured with a fluorescence microscope (EVOS FL Cell Imaging System, Life Technologies). For colocalization analysis of CCL2, confocal images of double-immunostained hippocampus sections were analyzed using a macro program designed by Daniel Shriwarski at the University of Pittsburgh in ImageJ software.

\section{Fluoro-Jade B staining}

The anionic fluorochrome Fluoro-Jade B (FJB) was used to stain degenerating neurons in brain sections. Briefly, tissue sections were air dried, and then immersed in $0.006 \%$ potassium permanganate solution for 15 min. Slides were washed briefly in water and then placed in $0.001 \% \mathrm{FJB}$ solution (Millipore Bioscience Research Reagents) in $0.1 \%$ acetic acid for $30 \mathrm{~min}$. The sections were dehydrated and cleared in xylene, air dried, and mounted with a coverslip. To quantify FJB-positive cells, three sections per mouse were selected. The numbers of FJB-positive cells from nine locations per mouse ( 3 fields per section $\times 3$ sections per mouse) were averaged and results are reported as the number of positive neurons per field of view and expressed as mean \pm SEM.

\section{Nissl staining}

For Nissl staining, hippocampal tissue sections were mounted and stained with $0.5 \%$ cresyl violet. The number of Nissl-stained neurons in a defined area CA1/CA3 $(1.0 \mathrm{~mm} \times 0.25 \mathrm{~mm})$ was counted in three fields of view per region per section in $\geq 3$ sections per mouse brain. All assessments of histological sections were blindly performed.

\section{Western blot}

Hippocampus samples were extracted and homogenized in lysis buffer containing protease and phosphatase inhibitors, and the homogenates were centrifuged at $7000 \times g$ for $15 \mathrm{~min}$ at $4^{\circ} \mathrm{C}$ as described previously (Wu et al., 2012). The supernatants were collected and the protein concentration was determined by Bradford method. For each lane, $30 \mu \mathrm{g}$ of proteins were loaded and separated by SDS-PAGE. After the transfer, the blots were incubated overnight at $4^{\circ} \mathrm{C}$ with one of the following primary antibodies: $\beta$-actin (1:5000, rabbit; Santa Cruz Biotechnology), RFP (1;
1000, rabbit; Sicgen), IL-1 $\beta$ ( $1 ; 1000$, rabbit; Abcam), Iba-1 (1:1000, rabbit; Wako), pSTAT3 (1:1000, rabbit; Cell Signaling Technology; detects tyrosine phosphorylation at Tyr705 of STAT3) or STAT3 (1:1000, rabbit; Cell Signaling Technology). These blots were then washed, incubated with HRP-conjugated secondary antibody, and developed in an enhanced chemiluminescent solution. Specific bands were evaluated by apparent molecular size. Finally, images were captured using a Fuji-Film LAS-300 imager(Fuji) and the intensity of the selected bands was analyzed using National Institutes of Health ImageJ software. For experiments to test blockage of CCL2 on monocyte infiltration, CCL2 neutralizing antibody or its isotype (100 ng in $5 \mu \mathrm{l}$ aCSF; Millipore) was administered intracerebroventricularly at $15 \mathrm{~min}$ before and 2 and $8 \mathrm{~h}$ after KA injection. The mice were killed $1 \mathrm{~d}$ after KA treatment.

\section{Cytokine array}

The mouse cytokine array kit precoated with 40 cytokine/chemokine antibodies was purchased from R\&D Systems. Protein samples were prepared in the same way as for Western blot analysis. Each reaction was performed according to the manufacturer's instructions using $150 \mu \mathrm{g}$ of proteins collected from the mouse hippocampus.

\section{Statistical analysis}

Data were expressed as mean \pm SEM. All statistical tests were performed using GraphPad Prism 5.0 (GraphPad Software). Quantitative data were compared between different groups by two-sample (unpaired Student's) two-tailed $t$ test assuming equal variance. Data for multiple comparisons were analyzed by two-way ANOVA followed by post hoc Student-NewmanKeuls tests. Instances for which a statistically significant difference was detected were indicated by asterisks: ${ }^{*} p<0.05 ;{ }^{* *} p<0.01$; $^{* * *} p<0.001$.

\section{Results}

\section{Chemokine CCL2 was upregulated and mainly expressed in microglia and neurons after status epilepticus}

Inflammatory cytokines are known to be critical for the pathogenesis of epilepsy (Dedeurwaerdere et al., 2012). To determine the change of cytokine expression after status epilepticus, we induced seizure activities in mice by intracerebroventrical injection of KA $(0.15 \mu \mathrm{g}$ in $5 \mu \mathrm{l}$ of aCSF $)$ and then performed a nonbiased protein screening using a cytokine/chemokine array that contains 40 different cytokine and chemokine antibodies (Fig. 1A). Hippocampal tissue lysates from control mice or from mice $1 \mathrm{~d}$ after KA-induced seizure were examined using the cytokine/ chemokine array. We found a marked increase in the levels of several chemokines, including CCL2, CCL3, CCL5, CCL12, and CXCL10, as well as of cytokines, including IL- $1 \alpha$ and IL- $1 \beta$. These results clearly indicate that KA-induced seizures significantly upregulated cytokine/chemokine expression $1 \mathrm{~d}$ after treatment.

To further study the function of seizure-associated cytokines and chemokines, we chose CCL2 for further characterization for the following reasons: (1) CCL2 expression is enriched in microglia (Leung et al., 1997; Zhang et al., 2014); (2) CCL2 is one of the most elevated inflammatory mediators in patients with epilepsy, but its contribution to seizure generation remains largely unknown (Cerri et al., 2016); (3) while the etiology of seizures is mostly idiopathic, infection is one of the few known risk factors of acquired epilepsy that is accompanied by increased macrophage infiltration in the brain (Marchi et al., 2014); (4) the blood-brain barrier is compromised following epilepsy (Marchi et al., 2012); and (5) the availability of both CCL2 $2^{-/-}$mice and $C C R 2^{-1-}$ mice enhances our ability to fully investigate the CCL2signaling pathway. Using Western blot, we confirmed that CCL2 was significantly upregulated $1 \mathrm{~d}$ after intracerebroventricular $\mathrm{KA}$ and maintained at high levels until $3 \mathrm{~d}$ after intracerebroventricular KA treatment (Fig. $1 B ; p<0.001$ ).

Next, to define the cellular distribution of CCL2, we performed immunofluorescence double staining of CCL2 with 
A

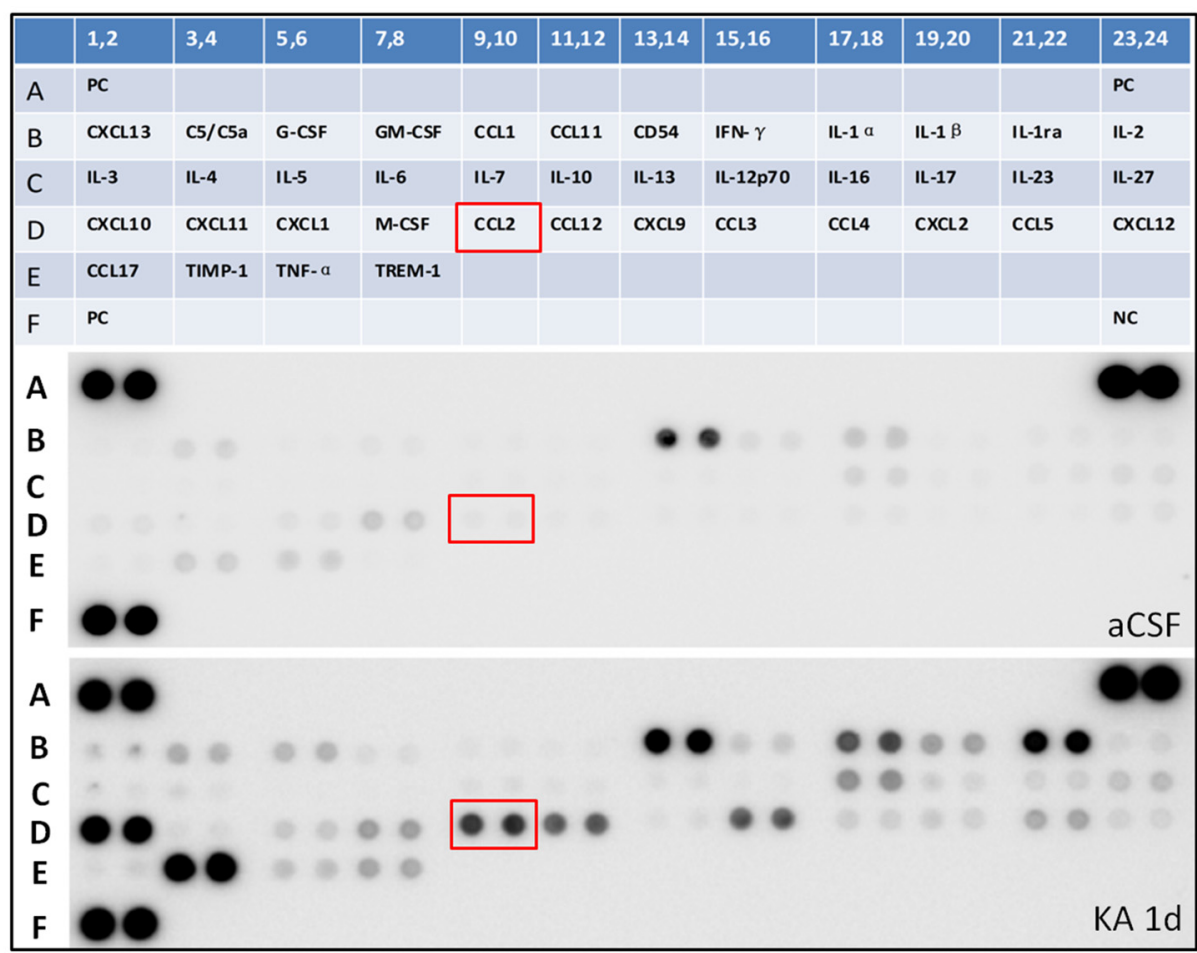

B
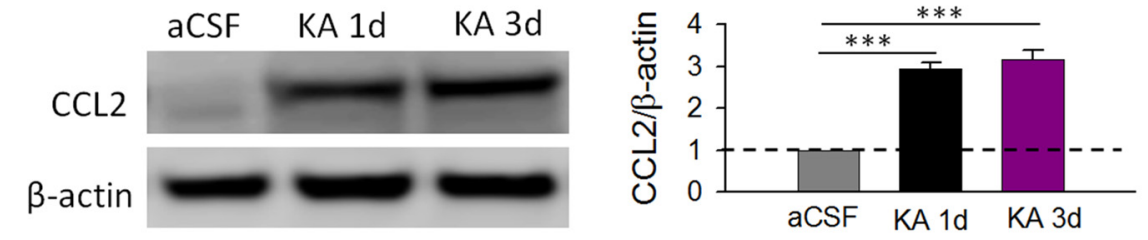

C
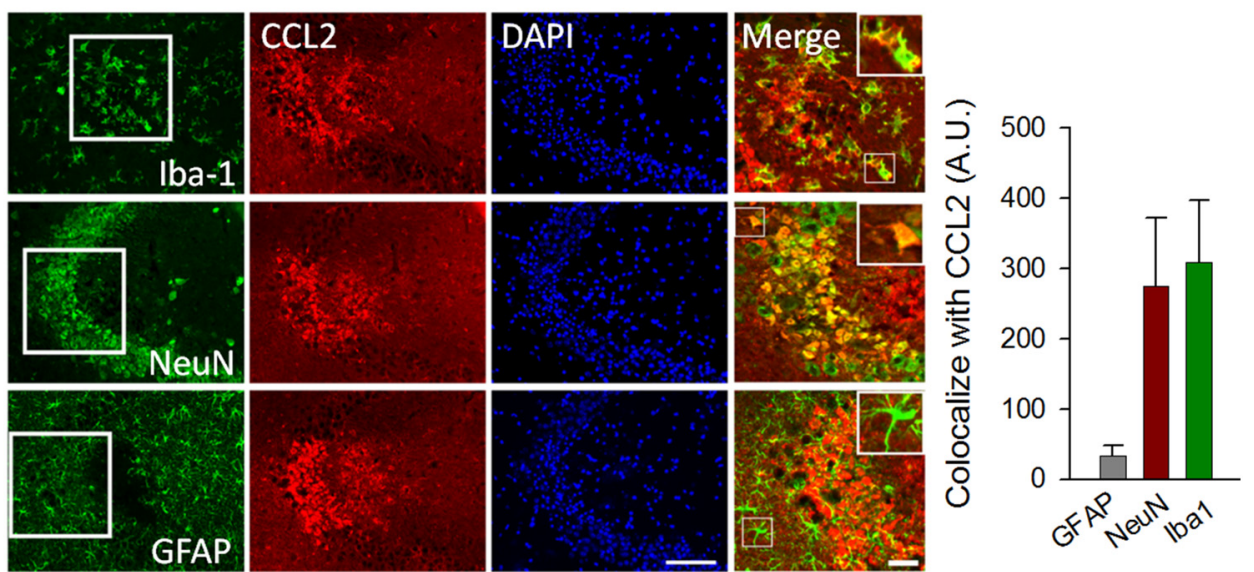

Figure 1. Elevated levels of CCL2 in the hippocampus after seizures. $A$, Top, Schematic representation of the cytokine array containing 40 different antibodies with duplicates. The array contains three positive controls ( $\mathrm{PC}$ ) and one negative control (NC). The expression level of cytokines/chemokines in the aCSF control (middle) and KA group (bottom) is shown. KA-induced seizures upregulated the expression of cytokines/chemokines, including CCL2 (D9,10), IL-1 $\beta$ (B19,20), IIMP1 (E3,4), CCL10 (D11,12), CCL3 (D15,16), CCI5 (D21,22), CXCL10 (D1,2), IL-1a (B17,18), and IL-1ra $(B 21,22)$ compared with those in the control group ( $n=3$ for each group). The red box highlights CCL2 (D9,10) expression in aCSF control and KA-treatment group. $\boldsymbol{B}$, left, Western blotting analysis shows an increase in CCL2 expression at 1 and $3 \mathrm{~d}$ after KA-induced seizures. Right, Summarized results showing relative CCL2/ $\beta$-actin in KA groups compared with relative CCL2/ $\beta$-actin in the aCSF control condition. $n=4$ for each group; ${ }^{* *} p<0.001$. C, Representative immunostaining images shows that the expression of CCL2 colocalized with microglial marker Iba-1 and neuronal marker NeuN, but not with astrocytic marker GFAP, in hippocampal CA3 area after seizures. DAPI staining was used to identify the cell nuclei. Scale bars: $100 \mu \mathrm{m} ;$ magnified merged figures, $50 \mu \mathrm{m}$. Summarized histogram shows colocalization of CCL2 with neuronal and microglial markers. Arbitrary unit (A.U.) is defined as percentage area of $C \mathrm{CL} 2$ stained region $\left(\mu \mathrm{m}^{2}\right)$ that colocalized with the neuron and glial markers ( $n=3$ for each group).

neuronal/glial cell markers in hippocampal CA3 area, where neuronal cell death is known to be prominent after intracerebroventricular KA treatment (Lee et al., 2003). Microglial marker Ibal, astrocyte marker GFAP, and neuronal marker NeuN were used.
In the control group, we found very weak expression of CCL2 (data not shown). However, CCL2 was dramatically upregulated and primarily expressed in microglia and neurons but not in astrocytes in hippocampal CA3 area $1 \mathrm{~d}$ after intracerebroven- 
tricular KA treatment (Fig. 1C). The specificity of CCL2 immunostaining was confirmed by lack of positive signals in KAinjected CCL2 ${ }^{-1-}$ mice (data not shown). Together, these results indicate that CCL2 is one of the key components upregulated after KA-induced seizures, and increased CCL2 is mainly expressed by hippocampal microglia and neurons.

\section{CCL2 chemokine induced macrophage infiltration in the hippocampus after seizures}

Next, we determined the role of CCL2 upregulation after KAinduced status epilepticus. Given that CCL2 acts via its receptor CCR2 in mediating macrophage infiltration (Cazareth et al., 2014), we hypothesized that the upregulated CCL2 after seizures induced the infiltration of blood-derived CCR2-positive monocytes. To test this hypothesis, we took advantage of double-transgenic $C C R 2^{R F P /+}: C X 3 C R 1^{G F P /+}$ mice, in which resident CX3CR1-positive microglia are labeled with GFP while CCR2-positive monocytes are labeled with RFP, to investigate the timeline of monocyte infiltration and microglia activation after KA-induced seizures. In the aCSF control group, we observed the occurrence of ramified GFP-positive resting microglia but not RFP-positive macrophages in the hippocampus. However, in mice after KA-induced seizures, we found that the RFP-positive cells, presumably infiltrated CCR2-positive macrophages, were increased at $1-3 \mathrm{~d}$ and started declining by $7 \mathrm{~d}$, whereas microglial activation increased progressively from 1 to $7 \mathrm{~d}$ after intracerebroventricular KA injection (Fig. $2 A, B$ ). Using Western blot, we confirmed the upregulation of both Iba1 expression and RFP levels at 1 and $3 \mathrm{~d}$ after KA injection (Fig. $2 D, E ; p<0.05$ ). These results directly demonstrated the infiltration of CCR2-positive macrophages after KA-induced seizures.

We further tested the idea that CCL2 is the chemokine that induced the infiltration of CCR2-positive macrophages. To this end, we administered CCL2-neutralizing antibody (100 ng in $5 \mu \mathrm{l}$ aCSF, i.c.v., three successive doses at $15 \mathrm{~min}$ before and 2 and $8 \mathrm{~h}$ after KA injection) in $C C R 2^{R F P /+}: C X 3 C R 1^{G F P /+}$ mice after status epilepticus. Indeed, we found that the infiltration of CCR2 ${ }^{\mathrm{RFP} /+}$ cells after seizure was largely reduced (Fig. 2C). Moreover, resident microglial activation after seizure was also diminished after the application of the CCL2-neutralizing antibody as evidenced morphologically (Fig. 2C). Consistently, we found that the treatment with CCL2-neutralizing antibody, but not isotype control antibody, suppressed KA-induced upregulation of both Iba1 and RFP levels in the hippocampus (Fig. $2 D, E ; p<0.05$ ). To further confirm that CCL2-CCR2 signaling was required for CCR2positive macrophage infiltration, $C C R 2^{-1-}$ mice were used (Fig. 2C). As expected, we found a reduced occurrence of Iba1-positive microglia/macrophages in $C C R 2^{-1-}$ mice at $1 \mathrm{~d}$ after KA-induced seizures. Together, our data indicated that upregulated levels of CCL2 after seizures induced the recruitment of CCR2-positive macrophages and subsequently caused, at least in part, microglial activation in the hippocampal CA3 area.

\section{CCR2-receptor deficiency did not alter the severity of acute seizures but attenuated neuronal degeneration after status epilepticus}

CCL2-CCR2 signaling has been shown to increase neuronal activity and neuronal cell death in a variety of neurological diseases, such as acute ischemic stroke and chronic Alzheimer's disease (Chen et al., 2003; Severini et al., 2014). However, little is known about the functional significance of CCL2-CCR2 signaling in status epilepticus. Here, we report the upregulation of CCL2 and infiltration of CCR2 macrophage $1 \mathrm{~d}$ after KA-induced seizures.
Therefore, we surmised that CCL2-CCR2 signaling may participate in the pathology of seizure-associated events, such as neuronal cell death. To address this question, we examined neurodegeneration and seizure behavior in $C C R 2^{-/-}$and $C C L 2^{-/-}$mice after intracerebroventricular injection of KA.

To begin, we used FJB, a fluorescent green dye that labels degenerating neurons, to detect neuronal degeneration in the hippocampus after seizures. In WT mice, we noted characteristic FJB staining localized mostly in the ipsilateral CA3 region of hippocampus $1 \mathrm{~d}$ after intracerebroventricular KA injection (Fig. $3 A$ ). However, $C C R 2^{-1-}$ and $C C L 2^{-1-}$ mice both displayed reduced FJB staining in the hippocampal CA3 area $1 \mathrm{~d}$ after KA injection (Fig. $3 B, C)$. We counted FJB-positive neurons and found dramatically fewer degenerating neurons in the epileptic brains of $C C R 2^{-1-}$ and CCL2 $2^{-1-}$ mice compared with brains of WT mice (Fig. 3D; $p<0.01$ ).

Next, we compared KA-induced acute seizure behaviors in age-matched $\mathrm{WT}, \mathrm{CCR} 2^{-/-}$, and $C C L 2^{-/-}$mice. Interestingly, during the initial $2 \mathrm{~h}$ of seizure observations, we found that neither $C C R 2^{-1-}$ nor $C C L 2^{-1-}$ mice displayed a significant difference in seizure Racine scores compared with WT mice (Fig. 3E; $p>0.05)$. In line with this, EEG measurements showed no significant difference in EEG scores between the WT, $C C R 2^{-/-}$, and $C C L 2^{-/-}$mice during the acute phase $(0-2 \mathrm{~h}$ after intracerebroventricular KA treatment; Fig. $3 F, G)$. Moreover, no recurrent seizures were observed during the chronic phase (7-14 d after intracerebroventricular KA treatment) in either WT, CCR2 $2^{-1-}$, or $C C L 2^{-1-}$ mice in our model of KA-induced seizure (data not shown). Together, the results suggest that CCL2-CCR2 signaling may not be directly relevant in acute seizure behaviors, but the reduced KA-induced neuronal death in $C C R 2^{-/-}$and $C C L 2^{-/-}$ mice implicates a critical role of the signaling in neuronal degeneration after status epilepticus.

\section{CCR2 is required for production of IL-1 $\beta$ after seizures}

To study the molecular mechanisms underlying CCL2-CCR2 signaling in neuronal degeneration after epilepsy, we turned to cytokine IL- $1 \beta$ because (1) it was upregulated after seizures in our cytokine/chemokine array (Fig. 1A), and (2) IL-1 $\beta$ is known to increase neuronal activities and neuronal degeneration in many disease conditions, such as epilepsy (Patel et al., 2006), Parkinson's disease (Koprich et al., 2008), and Alzheimer's disease (Kitazawa et al., 2011). Using Western blot, we indeed observed an increase in IL- $1 \beta$ levels at $1 \mathrm{~d}$ after KA-induced status epilepticus (Fig. $4 A$ ), consistent with that seen in the cytokine/ chemokine array (Fig. 1A). To test the role of CCR2 in IL-1 $\beta$ upregulation, we compared IL- $1 \beta$ levels in WT and CCR2 $2^{-/-}$ mice after intracerebroventricular KA treatment. Interestingly, we found that KA-induced IL- $1 \beta$ upregulation was largely abolished in $C C R 2^{-/-}$mice (Fig. $4 A, B ; p<0.05$ ). These results suggest that CCR2 is required for IL- $1 \beta$ upregulation after status epilepticus.

Next, we wanted to determine the cellular distribution of IL- $1 \beta$ after KA-induced seizures. To this end, we performed double immunostaining of IL- $1 \beta$ with neuronal and glial markers. We found that in WT aCSF control mice, IL- $1 \beta$ expression was low in the mouse hippocampus (Fig. $4 C, D$ ). However, there was dramatic upregulation in IL- $1 \beta$ levels after KA-induced seizures and the expression was strictly colocalized with Ibal (Fig. 4C,D). Consistently, IL- $1 \beta$ did not colocalize with GFAP or NeuN in the hippocampus after seizure (data not shown). In addition, using $C C R 2^{R F P /+}: C X 3 C R 1^{G F P /+}$ mice, we found that IL- $1 \beta$ was expressed in both CX3CR1-GFP microglia and CCR2-RFP macro- 
A
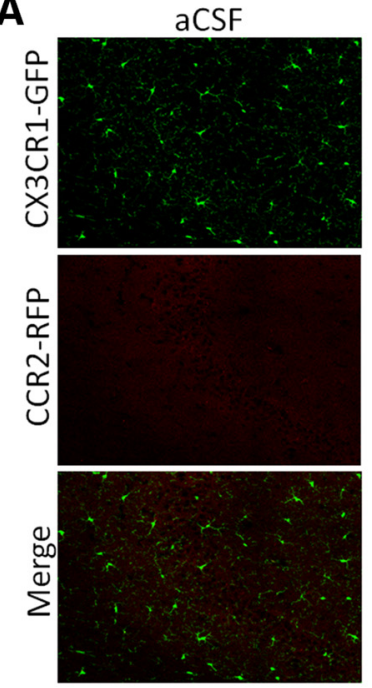

B

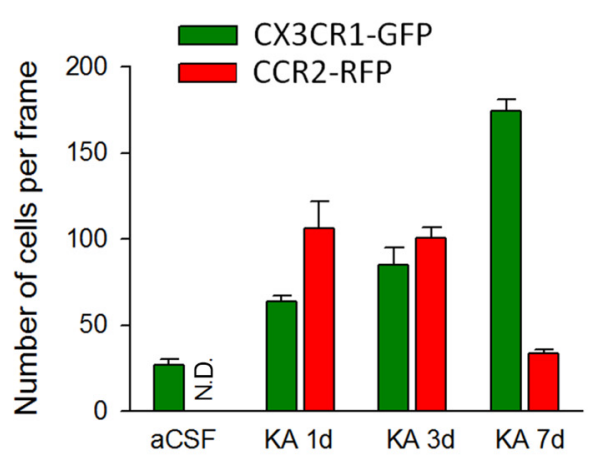

D

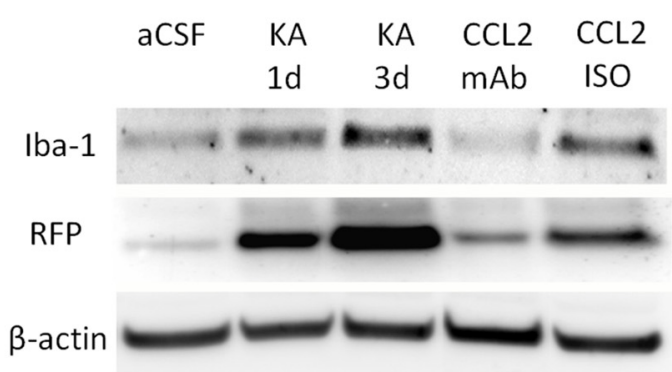

KA 1d
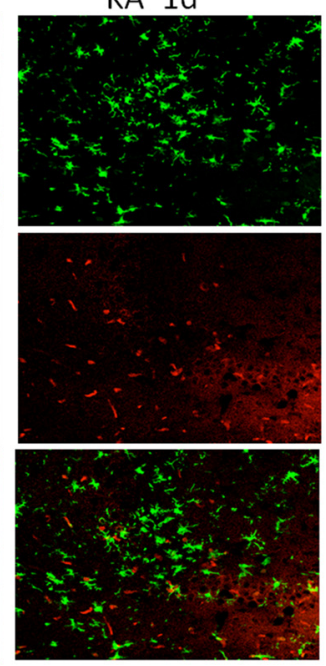

KA 3d
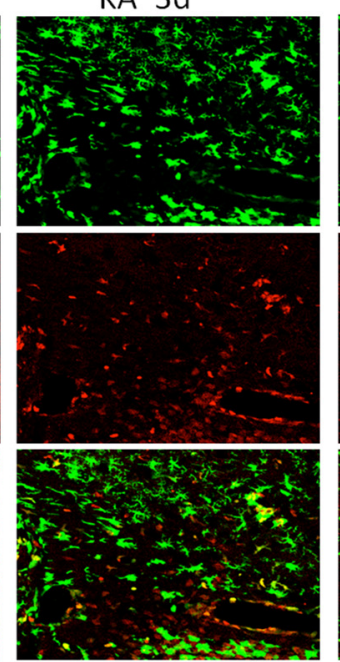

C

C CX3CR1-GFP

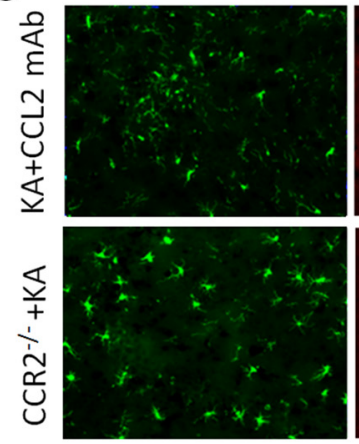

KA 7d
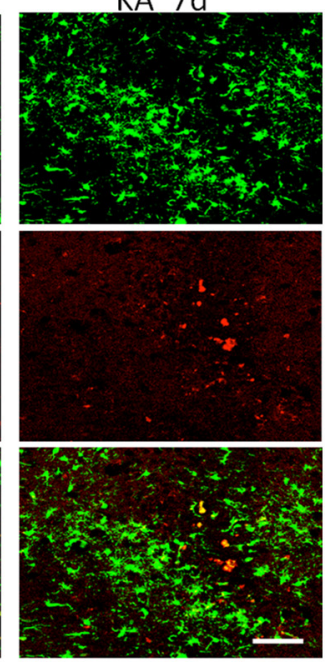

CCR2-RFP
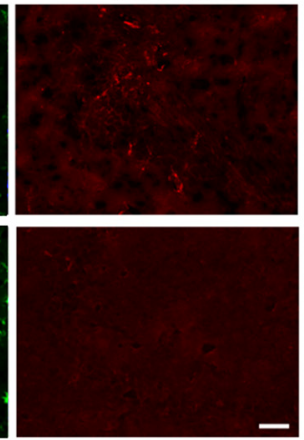

E
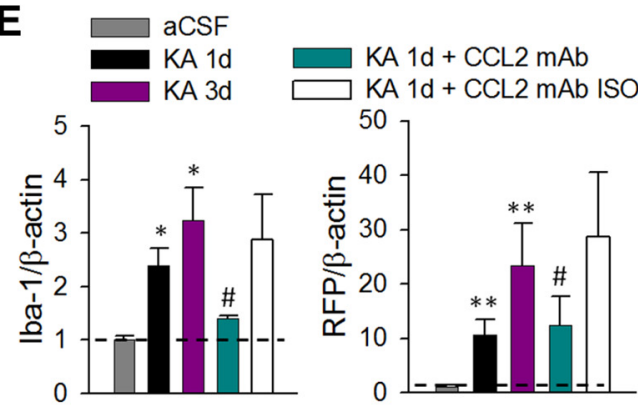

Figure 2. Microglial activation and macrophage infiltration in the hippocampus after status epilepticus. $\boldsymbol{A}$, Representative confocal images of hippocampus (CA3) in which CX3CR1-positive resident microglia are labeled with GFP and CCR2-positive macrophages are labeled with RFP in $C X 3 C R 1^{G F P /+}: C C R 2^{R F P /+}$ double-transgenic mice at 1, 3, and $7 \mathrm{~d}$ after KA-induced seizures and in the aCSF control group. Note that resident microglia become activated and CCR2-positive macrophages accumulate in hippocampal CA3 area 1 d after seizures. Scale bar, $100 \mu \mathrm{m}$. B, Quantitative analysis showing time course of CCR2-RFP macrophage infiltration and XX3CR1-GFP microglia activation at different time points following intracerebroventricular KA treatment. N.D., Not detected. Bars represent mean \pm SEM. C, Administration of CCL2-neutralizing antibody effectively suppressed infiltration of CCR2 RFP-positive cells, accompanied by the reduction in microglia activation 1 dafter KA treatment. Similarly, no infiltration of CCR2 RFP-positive cells was found in CCR2 ${ }^{-1-}\left(C X 3 C R 1^{G F P /+}: C C R 2^{R F P / R F P}\right)$ mice $1 \mathrm{~d}$ after KA treatment. Scale bar, $50 \mu \mathrm{m}$. D. Western blots of Iba-1, RFP, and $\beta$-actin in the hippocampus of aCSF control, $1 \mathrm{~d}$ after KA treatment, 3 dafter KA treatment, CCL2 mAb, and CCL2 isotype mice groups. The CCL2-neutralizing antibody or the isotype (100 ng in $5 \mu$ laCSF, i.c.v.) was administered 15 min before and 2 and 8 hafter KA injection and the mice were killed $1 \mathrm{~d}$ after KA treatment. $\beta$-Actin was used as loading control.E, The bar graphs represent densitometric analysis of theimmunoreactive blots. All data were normalized to aCSF control. $n=3$ for each group, ${ }^{*} p<0.05,{ }^{* *} p<0.01$ compared with aCSF group; $\# p<0.05$ compared with $1 \mathrm{~d}$ after KA treatment group.

phages (Fig. 4D). These results suggest that both activated resident microglia and infiltrated macrophages are sources for upregulated IL-1 $\beta$ after KA-induced seizures. This contrasts with results from another study that reported IL- $1 \beta$ release by reactive astrocytes in a rat model of temporal lobe epilepsy (Akin et al., 2011). We believe this discrepancy may be due to the difference in epilepsy model, animal species, and time course investigated, given that even minor strain differences can affect epilepsy outcome (Schauwecker, 2012). To confirm CCR 2 is required for IL- $1 \beta$ production after status epi- lepticus, we examined the expression of IL- $1 \beta$ in $C C R 2^{-/-}$mice. Indeed, we found compromised IL- $1 \beta$ expression in association with reduced microglial activation and macrophage infiltration in $C C R 2^{-1-}$ mice (Fig. 4C,D). Our results collectively showed that KA seizures induced production of IL- $1 \beta$ from microglia and macrophages is CCR2-dependent.

Given the reduced neuronal degeneration and the decreased IL- $1 \beta$ production in CCR $2^{-/-}$mice, we hypothesized that IL- $1 \beta$ may promote neuronal cell death after seizures. To test this hy- 
pothesis, we used IL-1 receptor antagonist (IL-1ra) to neutralize IL- $1 \beta$ and tested its effect on KA-induced neuronal degeneration. IL-1 ra was applied $15 \mathrm{~min}$ before and $2 \mathrm{~h}$ after the injection of KA $(0.5 \mu \mathrm{g}$ in $5 \mu \mathrm{l}$ aCSF, i.c.v., using the same stereotaxically placed cannula for KA) and then neuronal cell death was examined $1 \mathrm{~d}$ after seizures using FJB staining. We found that IL-1ra significantly decreased the number of degenerated neurons damaged by seizures (Fig. 4E, F; $p<0.05$ ). Therefore, IL-1 $\beta$ upregulation and probably release may promote neuronal cell death after status epilepticus and thus inhibition of IL$1 \beta$ was able to limit the hippocampal degeneration.

\section{STAT3 signaling in CCR2-dependent IL-1 $\beta$ production after seizures}

We have shown that CCR2 is required for IL- $1 \beta$ production from activated microglia and infiltrated macrophages after KAinduced seizures. To further examine the possible downstream signaling of CCR2 that leads to IL- $1 \beta$ production, we tested STAT3 signaling. STAT3 is critical for promoting the production of inflammatory cytokines (Qin et al., 2012; Przanowski et al., 2014) and is coupled to CCR2 activation in cancer cells (Izumi et al., 2013). First, we set out to investigate whether STAT3 is activated after status epilepticus. Since STAT3 activation requires its phosphorylation (Wen et al., 1995), we first performed immunostaining of pSTAT3 in the mouse hippocampus from aCSF control mice and from mice $1 \mathrm{~d}$ after KA injection. Consistent with the low basal STAT3 activity, we found pSTAT3 staining was low in aCSF control mice (Fig. 5A). However, pSTAT3 was highly expressed in the hippocampal CA3 after intracerebroventricular KA treatment (Fig. 5A). In addition, pSTAT3 expression mainly colocalized (90.85 \pm $1.64 \%$ ) with the microglial/macrophage marker Iba-1. To further examine pSTAT3 expression in resident microglia or infiltrated macrophages, we performed pSTAT3 staining in $C C R 2^{R F P /+}: C X 3 C R 1^{G F P /+}$ mice. Our results showed that pSTAT3 was expressed in both CX3CR1-GFP microglia and CCR2-RFP macrophages. These results suggest STAT3 signaling is upregulated in both activated resident microglia and infiltrated macrophages after KA-induced seizures.

Next, using $C C R 2^{-1-}$ mice, we determined whether CCR2 was involved in the activation of the STAT3 signaling pathway after seizures. Interestingly, we found that $C C R 2^{-1-}$ mice had decreased pSTAT3 levels compared with WT mice after KAinduced seizures (Fig. 5A). Western blot analysis was further used

$\mathbf{F}$
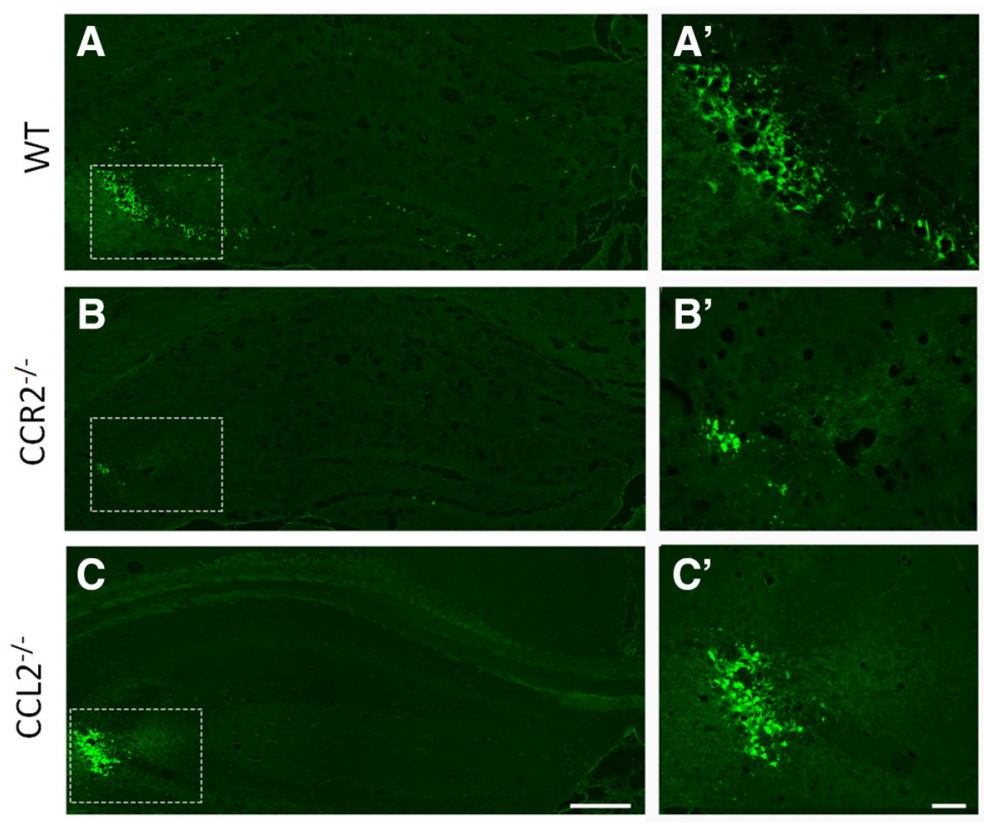

D

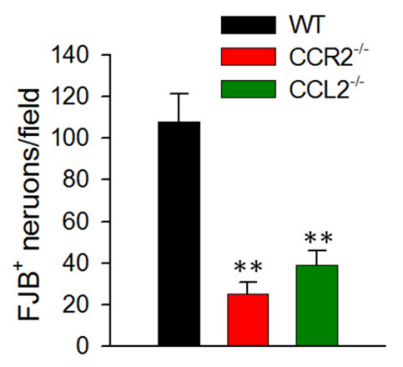

E

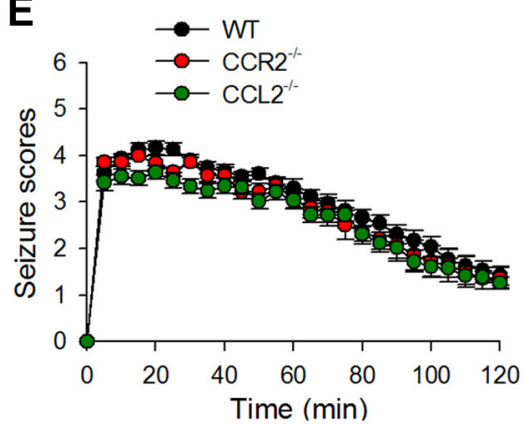

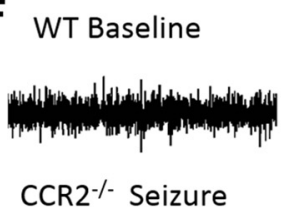

WT Seizure

G
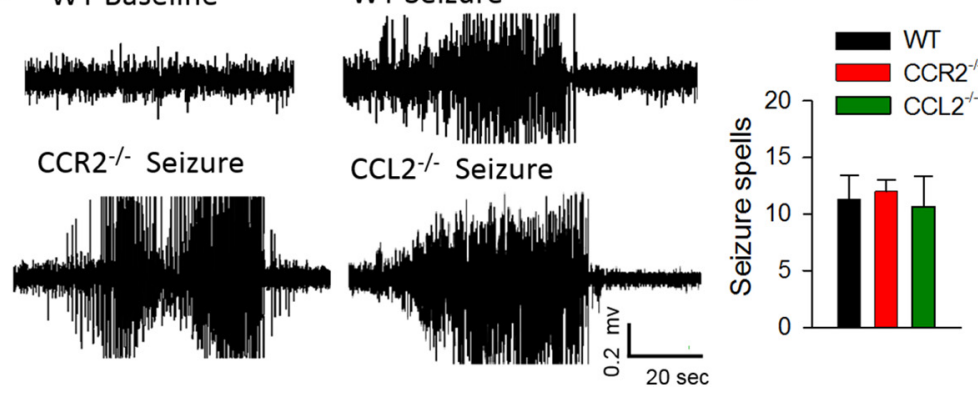

Figure 3. Decrease in the number of degenerated neurons in $\mathrm{CCR2}^{-1-}$ mice and $\mathrm{CCL}^{-1-}$ mice $1 \mathrm{~d}$ after KA treatment.

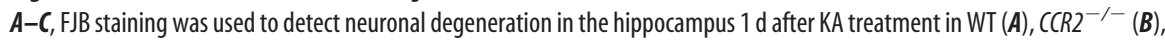
and $C_{C L 2}{ }^{-1-}(C)$ mice. Scale bar, $100 \mu \mathrm{m} . \boldsymbol{A}^{\prime}, \boldsymbol{B}^{\prime}, \boldsymbol{C}^{\prime}$, Magnified images for the rectangles shown in $\boldsymbol{A}-\boldsymbol{C}$, respectively. Scale bar, 50 $\mu \mathrm{m} . \boldsymbol{D}$, Quantification of number of FJB-positive neurons in WT, $C C R 2^{-1-}$, and $C \mathrm{CL} 2^{-1-}$ mice $1 \mathrm{~d}$ after KA-induced seizures. $n=$ 4 for each group, ${ }^{* *} p<0.01 . E$, Seizure scores $0-2 \mathrm{~h}$ after intracerebroventricular delivery of KA in WT, $C C R 2^{-/-}$, and $C C L 2^{-/-}$ mice. $n=9$ in WT, $n=6$ in $C\left(R 2^{-/-}\right.$, and $n=6$ in $C\left(L 2^{-1-}\right.$ mice, $p>0.05$. F, Representative EEG traces from awake WT, $C C R 2^{-1-}$, and $\mathrm{CCL2}^{-1-}$ mice before intracerebroventricular KA injection (baseline) and with stage 4 seizures after intracerebroventricular KA injection (seizure). $\mathbf{G}$, The histogram depicts total seizure spells detected between 0 and $2 \mathrm{~h}$ after KA administration in WT, $C\left(R 2^{-/-}\right.$, and $C C L 2^{-/-}$mice. Seizure spells were defined as high-frequency, high-voltage synchronized polyspike or paroxysmal sharp waves with amplitude $>2$-fold background and lasting $>6$ s. The peak-to-peak amplitude cutoff was set at $1000 \mu \mathrm{V} . n=3$ for each genotype of mice. 
A

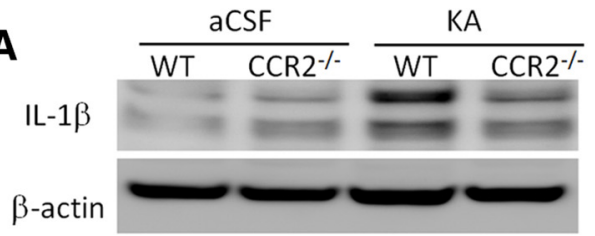

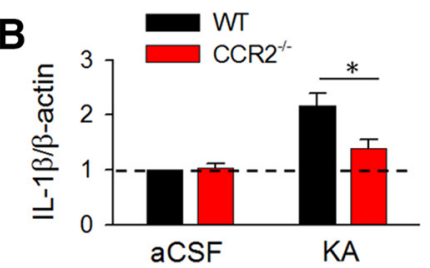

C
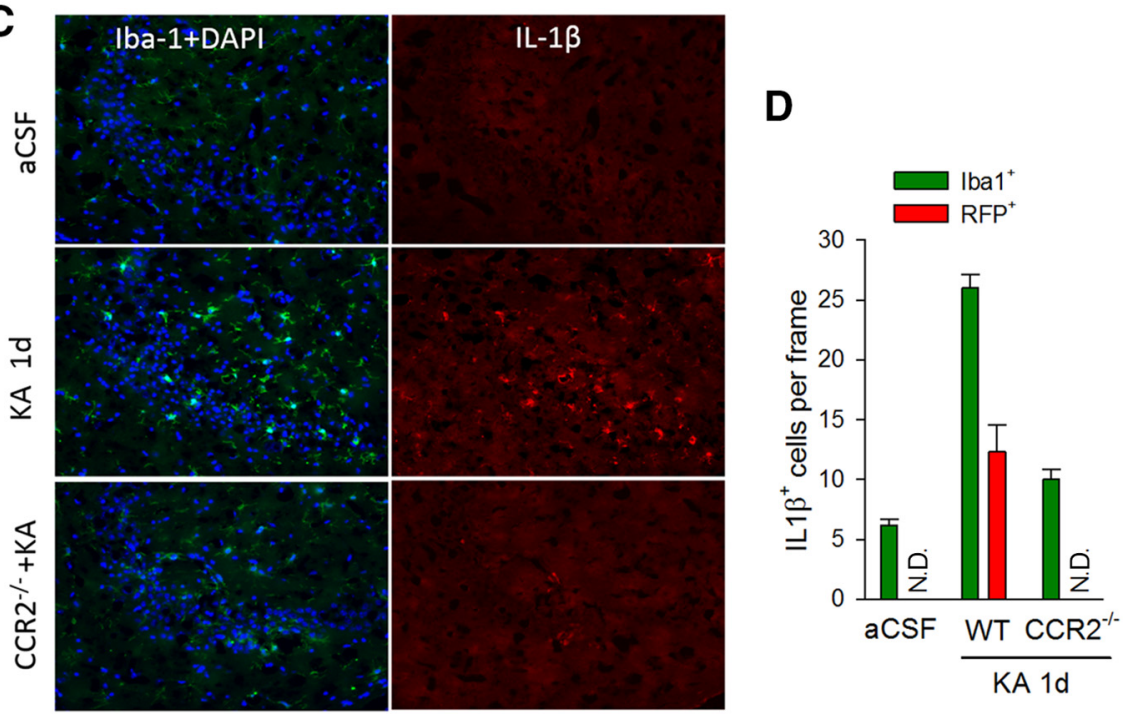

E
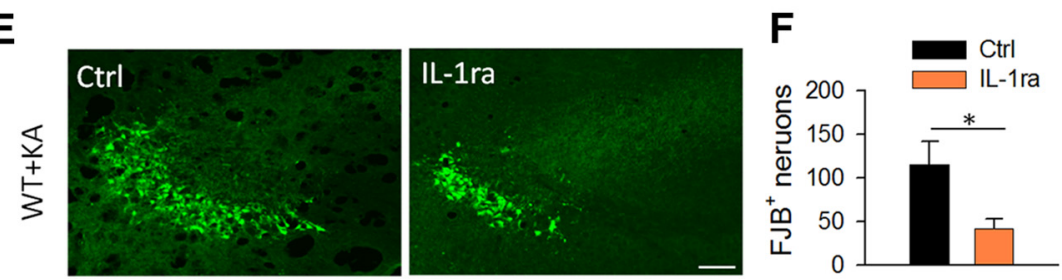

Figure 4. CCR2 deficiency reduces the production of proinflammatory cytokine IL-1 $\beta$ after status epilepticus. $A, B$, Western blots of $\mathrm{IL}-1 \beta$ level in the hippocampus of WT and $C C R 2^{-/-}$group. $\beta$-Actin was used as internal control. The graph represents densitometric analysis of the blots $1 \mathrm{~d}$ after KA treatment normalized to WT aCSF control. $n=4$ for each group; ${ }^{*} p<0.05$. C, Immunofluorescence images of CA3 hippocampal area from WT and $C_{C R 2^{-/-}}$mice $1 \mathrm{~d}$ after seizures showing colocalized expression of Iba- 1 and IL-1 $\beta$. DAPI was used for nuclear staining. Scale bar, $50 \mu \mathrm{m}$. D, Quantification of number of IL- $1 \beta^{+} \mathrm{Iba} 1^{+}$cells in WT mice as well as IL-1 $\beta^{+}$RFP ${ }^{+}$cells in $\mathrm{CX}_{3 \mathrm{CR}{ }^{G F P /+}}: C \mathrm{CR} 2^{\mathrm{RFP} /+}$ double-transgenic mice before and after intracerebroventricular KA treatment. KA-induced IL-1 $\beta$ upregulation was reduced in $\mathrm{CCL}^{-/-}$mice. $n=4$ for each group. N.D., Not detected. $E, F$, Administration of IL-1ra decreased the number of FJBpositive neurons in the hippocampus $1 \mathrm{~d}$ after seizure. Scale bar, $50 \mu \mathrm{m} . n=4$ for each group; ${ }^{*} p<0.05$.

Together, these results indicate that activation of microglia and macrophages after seizures was associated with the initiation of the STAT3-signaling pathway, which might be partially dependent on CCR2 activation.

Inhibition of STAT3 signaling decreased IL- $1 \beta$ production and neuronal degeneration after seizures

To further determine the role of STAT3 signaling following seizures, a potent STAT3 inhibitor WP1066 $(100 \mathrm{mg} / \mathrm{kg}$, i.p. $)$ was used $30 \mathrm{~min}$ before and $2 \mathrm{~h}$ after intracerebroventricular KA treatment and the expression of pSTAT3 was tested $1 \mathrm{~d}$ after intracerebroventricular KA treatment. A previous study showed that, despite the short half-life of WP1066, transient levels of WP1066 in vivo in the brain and plasma was sufficient to reduce chronic seizure severity in a pilocarpine model of epilepsy (Grabenstatter et al., 2014). Consistent with their study, we confirmed that WP1066 effectively inhibited the levels of pSTAT3 without reducing the expression of total STAT3 (Fig. 6A, B; Grabenstatter et al., 2014). Since we have shown that both STAT3

activation and IL- $1 \beta$ production require CCR2 after status epilepticus, we tested whether STAT3 signaling acts upstream of IL- $1 \beta$. To test this idea, we examined the effect of STAT3 inhibition by WP1066 on IL- $1 \beta$ production after seizures. Indeed, we found that in addition to suppressing STAT3 phosphorylation, WP1066 significantly attenuated IL-1 $\beta$ production and Ibal levels (Fig. $6 A, B ; p<0.05$ ). Therefore, these results indicate that STAT3 signaling is upstream of IL- $1 \beta$ production and microglial activation after seizures.

Since STAT3 signaling is required for IL- $1 \beta$ production, we surmised that the inhibition of STAT3 by WP1066 would rescue KA-induced neuronal degeneration. To this end, we studied the effect of WP1066 on neuronal degeneration after status epilepticus by FJB staining. WP1066 was applied 30 min before and $2 \mathrm{~h}$ after intracerebroventricular KA treatment and neuronal cell death was assessed $1 \mathrm{~d}$ after KA treatment. We found that the number of FJB-positive neurons in the CA3 region decreased significantly after WP1066 treatment compared with those with vehicle treatment (Fig. $6 C, D ; p<$ $0.05)$. However, the severity of the acute seizure scores after WP1066 treatment was similar to that in the vehicle-treated group (Fig. $6 E ; p>0.05$ ). This contrasts with the findings of a previous study, which reported that WP1066 did not affect cell death, although it affected chronic seizure severity (Grabenstatter et al., 2014). The discrepancies between findings related to WP1066 in neuronal cell death and seizure severity might be due to the different status epilepticus models that were used. Indeed, intracerebroventricular KA-induced status epilepticus causes localized neuronal death in hippocampal CA3, while pilocarpine-induced status epilepticus is more widespread in hippocampal CA1, CA3, and hilus. Also, as opposed to the pilocarpine model, the intracerebroventricular KA model failed to induce chronic seizures, as recorded by EEGs, even in WT mice (data not shown). Therefore, the molecular mechanisms underlying the cell death and seizure severity in the two models could be different. Together, our results show that although WP1066 treatment did not prevent the development or reduce the severity of acute seizure behaviors, it was able to inhibit neuronal cell death after KA-induced status epilepticus. Together, these results indicate that STAT3 signaling may act as a mediator for CCR2induced IL- $1 \beta$ production in activated microglia and infiltrated macrophages, leading to neuronal degeneration after seizures.

\section{CCR2 deficiency attenuates seizure-induced behavioral impairments beyond the acute injury}

To study the functional significance of CCL2-CCR2-dependent acute neuronal death after KA-induced status epilepticus, we examined the pathology and behaviors $14 \mathrm{~d}$ after KA treatment in 
WT and $C C R 2^{-/-}$mice. Nissl staining was used to investigate the neuronal loss in the CA1 and CA3 region of the hippocampus $14 \mathrm{~d}$ after KA treatment, since the FJB method more accurately measures acute neuronal degeneration. We observed a characteristic loss of pyramidal neurons in WT mice, which is consistent with increased FJB staining $1 \mathrm{~d}$ after KA treatment. There was no significant difference in neuronal survival between WT and $C C R 2^{-/-}$mice in the CA1 region (data not shown). However, there were more surviving neurons in the CA3 of $C C R 2^{-/-}$mice compared with WT mice $14 \mathrm{~d}$ after KA treatment (Fig. $7 A ; p<$ 0.001). Therefore, the tendency of neuronal loss shown by Nissl staining in the chronic seizure stage correlated with that seen in the acute stage shown by FJB staining $1 \mathrm{~d}$ after seizure (Fig. 3B), suggesting that the CCL2-CCR2 signaling contribution to neuronal death persists in the chronic phase of epilepsy.

Epilepsy is often associated with behavior alterations, such as anxiety and impaired cognitive performance (Caplan et al., 2008). Hence, we wanted to test the implications of CCL2-CCR2-dependent hippocampal neurodegeneration in anxiety and cognition in a KA-induced seizure model. Anxiety-related behavior was evaluated by analyzing the time/distance that mice traveled in the center of the open field. Under control condition with aCSF injection, there was no significant difference between WT and $C C R 2^{-1-}$ mice in the time spent in the center. However, at 7 or $14 \mathrm{~d}$ after injection of KA, the WT mice, compared with CCR2 $2^{-/-}$mice, spent less time in the center, suggesting that epilepsyinduced anxiety-like behavior is reduced in $C C R 2^{-/-}$mice (Fig. $7 B ; p<0.05)$. Similarly, WT mice, compared with $C C R 2^{-1-}$ mice, traveled less distance in the central area (data not shown). As a control, we found no significant difference in total distance between WT and CCR2 $2^{-1-}$ mice (data not shown). Next, we used novel-object recognition to examine hippocampal-dependent cognitive function and to investigate whether cognitive decline is more evident in WT mice than in $C C R 2^{-/-}$mice. Administration of KA to WT mice induced cognitive decline in agreement with previous reports (Matsuda et al., 2015). Indeed, CCR2 deficiency attenuated this seizure-induced cognitive decline, although in the control group, WT and CCR2 $2^{-/-}$mice showed no significant difference (Fig. 7C).

We found no significant difference in acute seizure scores between the WT and $C C R 2^{-/-}$following the KA injection, but CCR2 deficiency reduced KA-induced neuronal cell death (Fig. $3)$. Here we tested the severity of recurrence of seizures following $\mathrm{KA}$ reinjection $14 \mathrm{~d}$ after the first KA injection (Fig. 7D). Interestingly, we found that the second dose of KA ( $14 \mathrm{~d}$ after the first KA injection) evoked more severe seizures in WT mice compared with $C C R 2^{-/-}$mice. The WT group presented a drastically higher mortality rate and seizure score within the first hour after the second KA injection (Fig. 7D). Together, these results suggest that CCL2-CCR2 signaling exacerbates neuronal loss, seizureinduced cognitive decline, and increased seizure severity upon secondary seizure induction in the chronic stage of KA-induced epilepsy.

\section{Discussion}

In the current study, we delineate an intriguing molecular cascade underlying CCL2-CCR2 signaling in neuronal cell death after status epilepticus (Fig. 8). At $1 \mathrm{~d}$ following KA-induced seizures, hyperactive neurons and microglia release CCL2, triggering CCR2-positive monocyte infiltration. Activation of CCR2 is coupled to the STAT signaling pathway and subsequent production of IL- $1 \beta$ by both microglia and macrophages, which in turn promotes neuronal cell death after seizures. Our results suggest a critical role for CCL2-CCR2 signaling in neuronal cell death after status epilepticus, identifying it as a potential therapeutic target for the management of epilepsy.

\section{CCL2-CCR2 signaling in macrophage infiltration after seizures}

Increasing evidence based on observations made from experimental animals and human patients suggests that the 
A

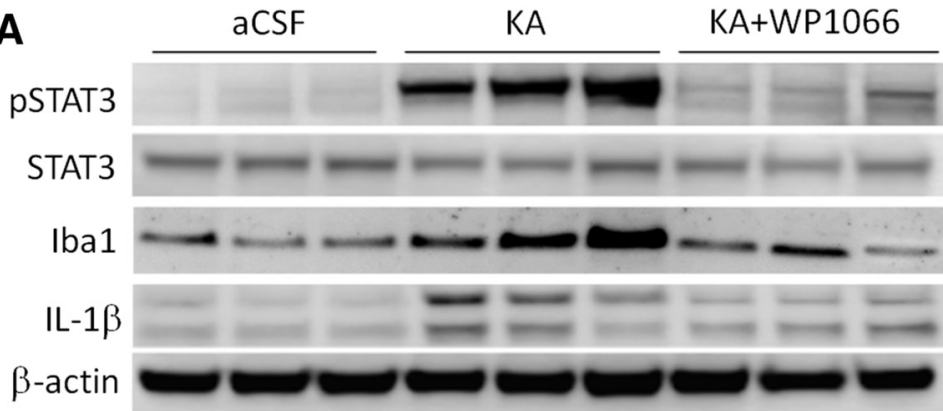

B

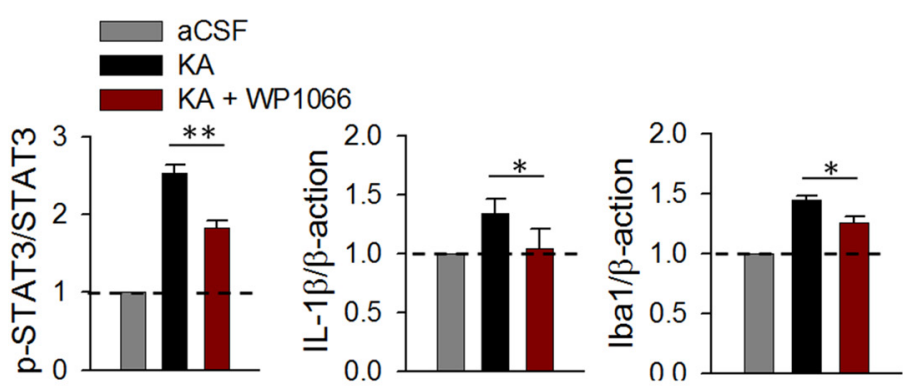

C
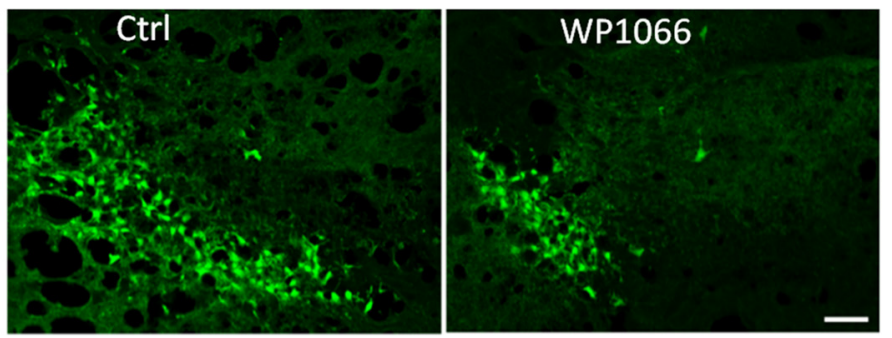

D

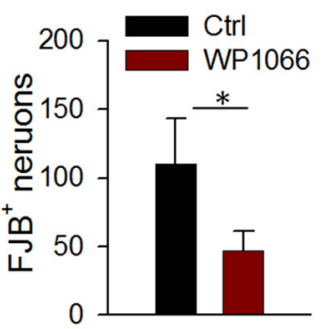

E

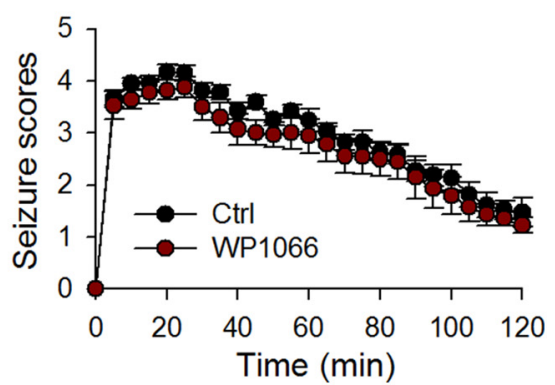

Figure 6. Inhibition of PSTAT3 reduces production of proinflammatory cytokine IL- $1 \beta$ and neuronal degeneration induced by seizures. $\boldsymbol{A}$, Western blots of pSTAT3, STAT3, Iba-1, and IL-1 $\beta$ in the hippocampus of aCSF, KA+vehicle, and KA+WP1066 treatment group. $\beta$-Actin was used as loading control. $\boldsymbol{B}$, The summarized results showing the bar graphs represent densitometric analysis with each bar representing the ratio of optical density of pSTAT3 level to that of STAT3 (left), IL- $1 \beta$ to that of $\beta$-actin (middle), or lba- 1 to that of $\beta$-actin (right). All data were normalized to aCSF control. $n=3$ for each group; ${ }^{*} p<0.05$; ${ }^{* *} p<0.01$. $C, D, F J B$ staining was used to detect neuronal degeneration in the hippocampus $1 \mathrm{~d}$ after KA treatment; the data are represented qualitatively $(\boldsymbol{C})$ and quantitatively $(\boldsymbol{D})$ showing that WP1066 reduces seizure-induced FJB staining. Scale bar, $50 \mu \mathrm{m}$. $\boldsymbol{E}$, The graph represents seizure scores of mice treated with vehicle and WP1066 $1 \mathrm{~d}$ after KA injections. $n=6$ mice each group; ${ }^{*} p>0.05$.

neuroinflammatory response may be a potential contributor to seizure-related pathologies (Vezzani et al., 2011; Janigro et al., 2013). It is not clearly known whether the inflammatory response underlies epileptogenesis or exacerbates the damage after the onset of seizures. Seizure-induced inflammatory responses, including activation of glial cells and secretion of inflammatory mediators, are known to increase neuronal hyperactivities, thereby promoting neuronal cell death during epilepsy (Vezzani and Viviani, 2015). However, the molecular mechanisms un- derlying the role of inflammation in epileptic neuronal death are still largely unknown. In this study, we found an array of chemokines, including CCL2, CCL3, CCL5, CCL10, and CXCL10, that are upregulated $1 \mathrm{~d}$ following KA-induced seizures. This is consistent with previous studies that reported an increase in CCL2 levels in rodent brains after acute seizures (Manley et al., 2007; Foresti et al., 2009) and in brain tissue of epilepsy patients (Wu et al., 2008; Choi et al., 2009). Our study further determined the cell types expressing CCL2 and showed that the elevated CCL2 expression was predominantly localized in microglia and neurons. Future studies are needed to address how CCL2 is upregulated and whether common mechanisms are used to increase the CCL2 expression in neurons and microglia.

It has been reported that CCL2 is able to induce monocyte recruitment into the CNS after experimental autoimmune encephalomyelitis and ischemic stroke (Che et al., 2001; Huang et al., 2001; Hughes et al., 2002; Semple et al., 2010). Indeed, our study directly demonstrated the role of CCL2 in macrophage infiltration through CCR2 activation after seizures using two complementary approaches: (1) We observed blood-born CCR $2^{R F P /+}$ cells in the hippocampus after seizures, which was inhibited by a CCL2-neutralizing antibody; (2) There is absence of macrophage infiltration in $C C R 2^{-/-}$mice after $\mathrm{KA}$ induced status epilepticus. In addition to CCL2 upregulation, the expression of its receptor CCR2 was also notably increased after seizures. Considering the infiltration of CCR2-postive macrophages in the hippocampus, the upregulated CCR2 was likely due to the increased macrophages after seizures. Interestingly, we also noted that blocking CCL2 not only reduced macrophage infiltration, as evidenced by reduced Ibal expression, but also reduced the activation of resident microglia, as evidenced morphologically. This suggests that macrophage infiltration may trigger activation of endogenous microglia after seizure induction and is worthy of further investigation. Microglia and CCR2-positive macrophages are shown to play differential roles in the inflamed brain with the monocyte-derived macrophages being highly phagocytic and inflammatory, whereas microglia demonstrate an unexpected signature of globally suppressed cellular metabolism at disease onset (Yamasaki et al., 2014). The deficiency of CCR2 reduced overall pSTAT3 and IL- $1 \beta$, which indicates that CCL2-CCR2 signaling is critical to trigger the cascade in infiltrated macrophages as well as in resident microglia. Interestingly, a recent study identified CCR2 expression in neuronal progenitors (Hung et al., 2013). However, we did not observe CCR $2^{\mathrm{RFP} /+}$ cells in the dentate 
A

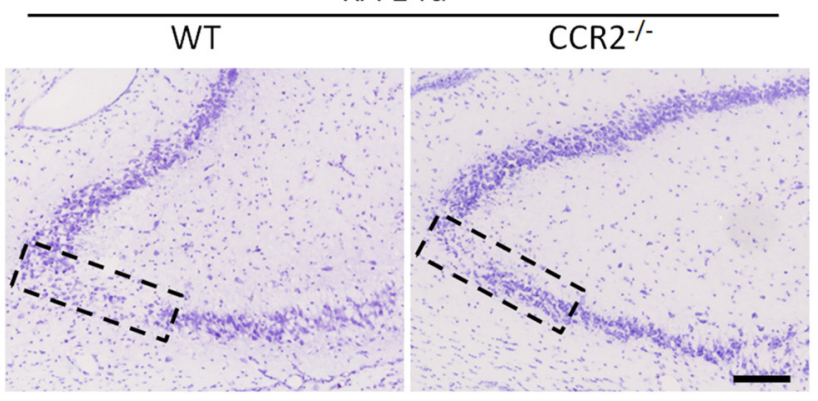

B

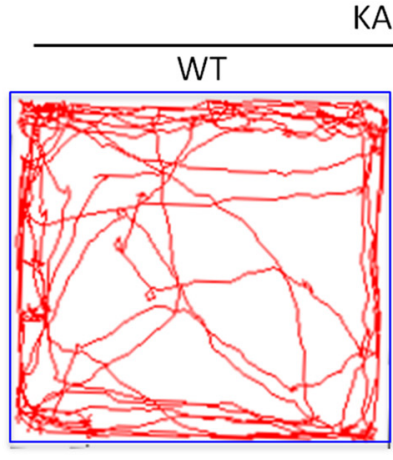

KA 14d

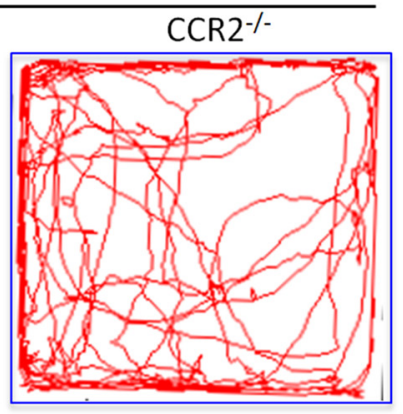

D
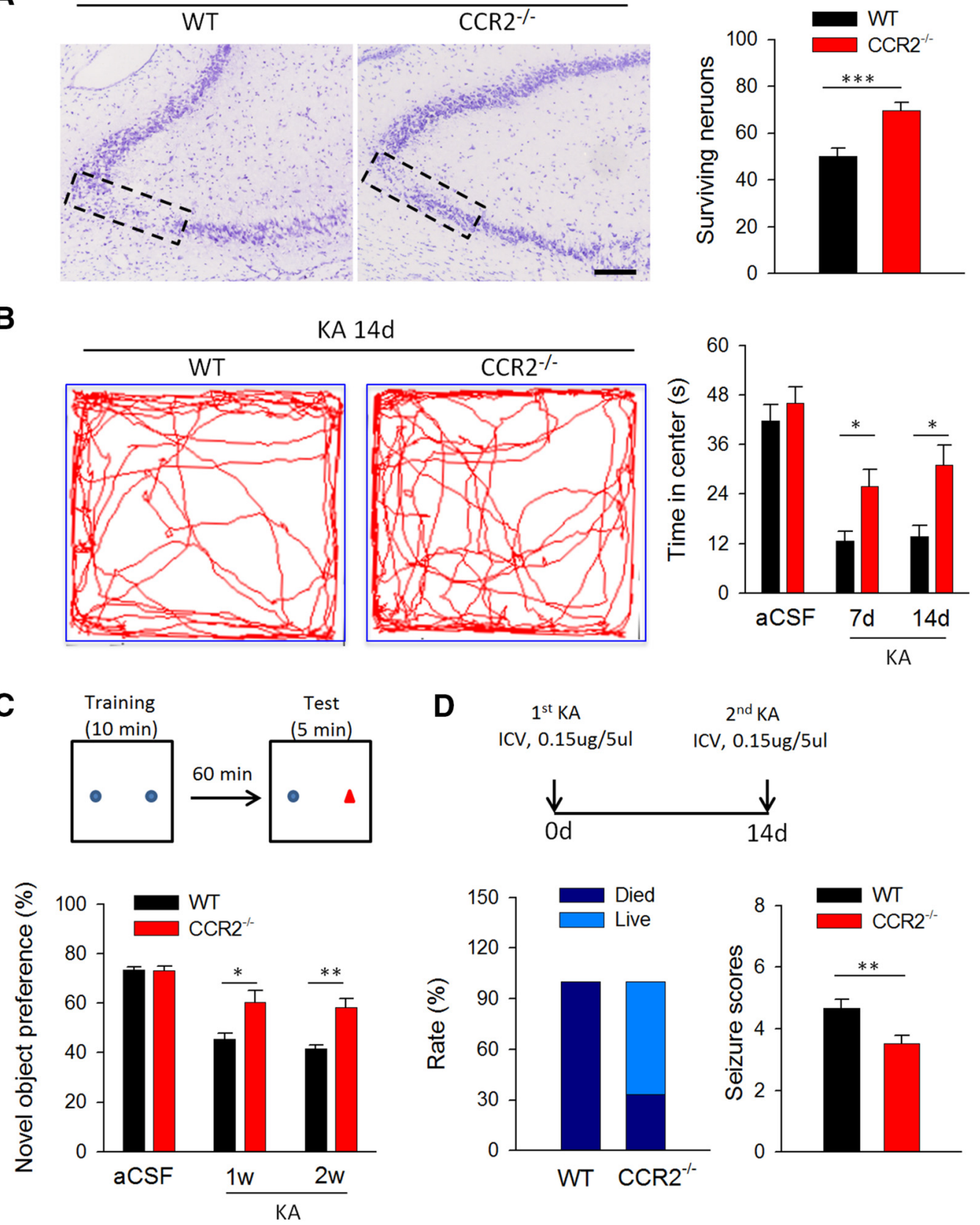

C

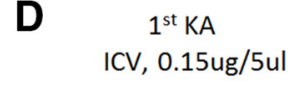

$2^{\text {nd }} \mathrm{KA}$

ICV, 0.15ug/5ul
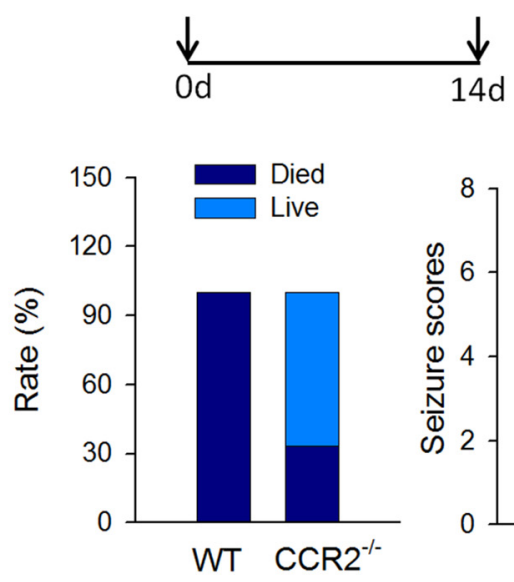

Figure 7. CCR2 deficiency attenuates seizure-induced behavioral impairments. $A$, The number of surviving neurons in Nissl-stained sections was counted in the CA3 area of the ipsilateral side of the hippocampus in WT and $C C R 2^{-1-}$ mice $14 \mathrm{~d}$ after KA injection. $n=5$ for each group, ${ }^{* * *} p<0.001$. Scale bars, $50 \mu \mathrm{m}$. B, Open-field test was used to examine anxiety behaviors of WT and $C\left(R 2^{-\prime-}\right.$ mice at 7 and $14 \mathrm{~d}$ after KA treatment. Representative traces (left) and summarized data (right) show that WT mice, compared with $C C R 2^{-1-}$ mice, spent less time in the center of the open field at both 7 and $14 \mathrm{~d}$ after KA injection. $n=8$ and 5 for aCSF-injected and KA-injected group (WT mice and CCR2 ${ }^{-/}$mice) respectively; ${ }^{*} p<0.05$; ${ }^{* *} p<0.01$. C, Novel-object recognition was used to detect hippocampal-dependent memory change following KA-induced seizures. The preference for the novel object was significantly higher in $C^{C} R 2^{-\prime-}$ mice than in WT mice. $n=8$ and 5 for aCSF-injected and KA-injected group (WT mice and CCR2 ${ }^{-1-}$ mice) respectively; ${ }^{*} p<0.05$; ${ }^{* *} p<0.01$. D, A second dose of KA $(0.15 \mu \mathrm{g} / 5 \mu$, i.c.v.) $14 \mathrm{~d}$ after first KA injection (0.15 $\mu \mathrm{g} / 5$ $\mu \mathrm{l}$, i.c.v.) induced recurrent seizure. Left, Percentage (Rate) of mice that survived (Live) compared with the percentage of mice that died among WT and $C_{C\left(R 2^{-1}\right.}$ mice. Right, Score of recurrent seizures among WT and $C\left(R 2^{-/-}\right.$mice. Since all WT mice died within $60 \mathrm{~min}$ of KA injection, the mean seizure score was also counted within the first hour after second KA injection. $n=5$ for each group; ${ }^{* *} p<0.01$.

gyrus, the region of origin of neuronal progenitors in our transgenic mice. The discrepancy might be due to the differences in animal species used, methods for CCR2 detection, or models for the seizure induction.

Previous studies have demonstrated that CCL2 can activate macrophages by binding to CCR2 expressed on the surface of these cells (Rollins, 1991). CCR2 activation triggers monocyte adhesion to inflamed endothelium via $\beta$-integrin pathways (Shi and Pamer, 2011). Therefore, monocyte CCR2 promotes its attachment to endothelial cells and subsequent infiltration into the brain parenchyma. We have shown that seizures induced the upregulation of CCL2, activated CCR2, and triggered monocyte infiltration. Indeed, the number of CCR2-positive macrophages was suppressed by neutralizing CCL2 in WT mice, as well as in $C C R 2^{-/-}$mice. However, it is still unknown whether neuronal CCL2 and microglial CCL2 play different roles in attracting CCR2- 


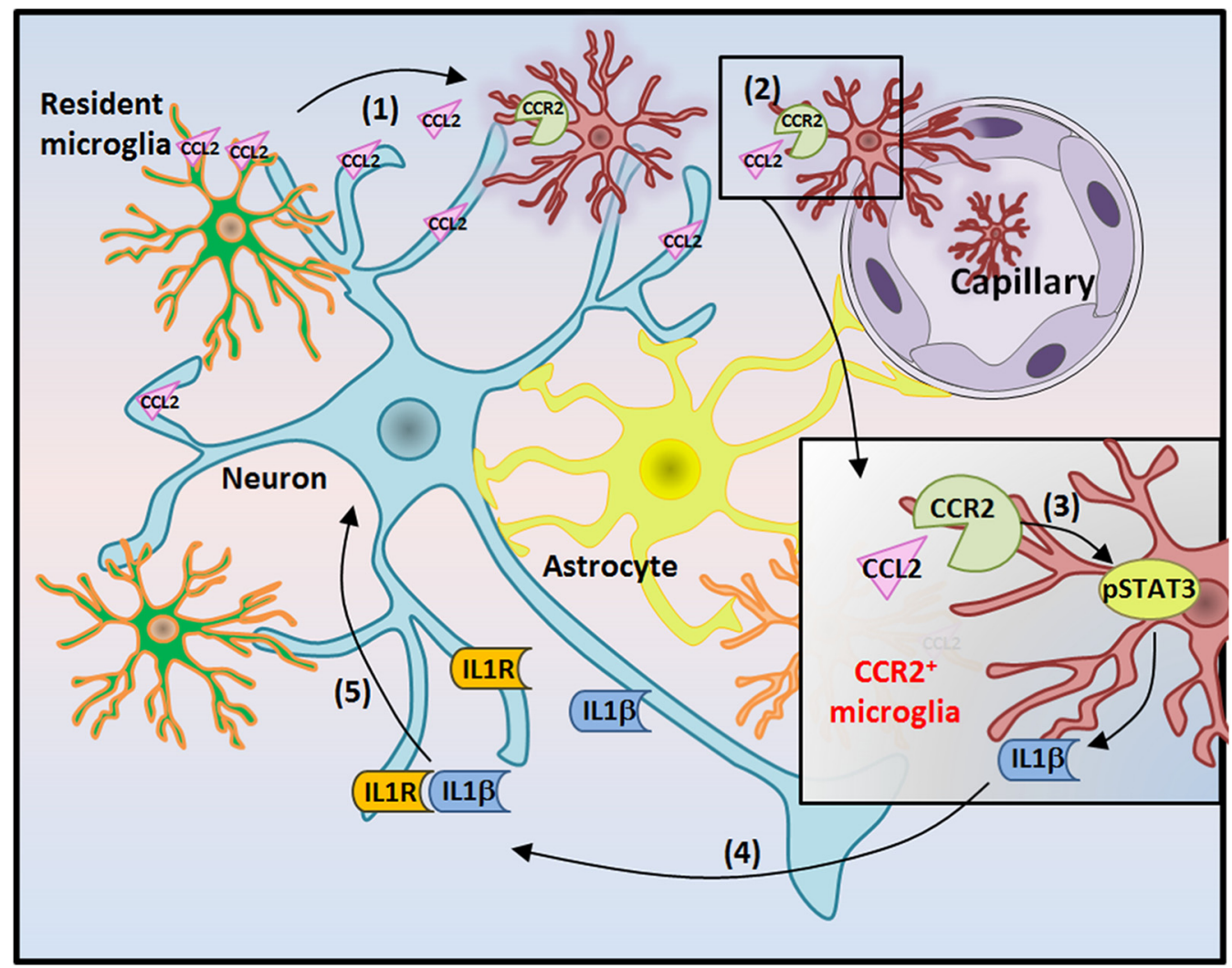

Figure 8. Schematic representation of CCL2-CCR2 signaling in causing neuronal cell death via STAT3 activation and IL-1 $\beta$ production after status epilepticus. After KA-induced seizure, the following processes occur: (1) CCL2 is upregulated and released from neurons/microglia; (2) CCL2 increases, aiding in CCR2-positive monocyte infiltration; (3) CCL2-CCR2-dependent activation of pSTAT3 mediates macrophage infiltration and microglia activation; (4) IL- $1 \beta$ is upregulated and released from activated microglia/macrophages; (5) IL-1 $1 \beta$ produced by microglia/macrophages induces neuronal cell death. Consistently, both $\mathrm{CCL}^{-/-}$mice and $\mathrm{CCR}^{-/-}$mice have the phenotype of less neuronal death $1 \mathrm{~d}$ after KA-induced seizures.

positive monocytes into the injured CA3 area. Nevertheless, our findings indicate a critical role for CCL2-CCR2 signaling in macrophage infiltration in the mouse hippocampus after seizures.

\section{CCL2-CCR2 signaling and neuronal cell death in epilepsy}

Status epilepticus results in neurodegeneration in the hippocampus, a prominent feature in clinical epilepsy (Thom, 2014). Previous studies have associated CCL2 with excitotoxic neurodegeneration (Kalehua et al., 2004; Sheehan et al., 2007). However, the underlying molecular mechanism remained to be elucidated. Elevated levels of STAT3 signaling have been documented in rats following pilocarpine-induced status epilepticus (Grabenstatter et al., 2014). In the present study, we found that CCL2-CCR2 signaling activates the STAT3 pathway and subsequent IL-1 $\beta$ production. Consistently, the upregulation of pSTAT3 was attenuated in $C C R 2^{-/-}$mice. In addition, WP1066, a potent STAT3 inhibitor suppressed the seizure-induced increase in expression of the microglial maker Iba- 1 and inflammatory cytokine IL-1 $\beta$. Although our study does not clearly differentiate the contribution of pSTAT3 on microglial activation versus monocyte infiltration, our results indicated a critical role for pSTAT3 in CCL2/CCR2-mediated microglial activation and IL- $1 \beta$ production. In line with our study, recent studies also demonstrated that CCL2-CCR2 signaling plays an important role in STAT3 activation in cancer metastasis (Izumi et al., 2013; Lin et al., 2013), as well as in epithelialmesenchymal transition (Chen et al., 2015).

We further showed that increased IL- $1 \beta$ production in microglia/macrophages may promote neuronal cell death based on sev- eral lines of evidence, including the following: (1) the decrease in the number of degenerated neurons after seizures, because of the IL-1 receptor antagonist, which is consistent with previous reports (Allan et al., 2005); (2) the decrease in IL- $1 \beta$ production and cell death after seizures in CCR2 $2^{-/-}$mice and CCL2 $2^{-/-}$mice; and (3) the inhibition of STAT3 accompanied by attenuation in IL- $1 \beta$ production and neuronal cell death. Consistently, recent studies have shown that IL- $1 \beta$ enhanced seizure susceptibility and neuronal cell death after prolonged febrile seizures (Fukuda et al., 2014), whereas pharmacological blockade of IL-1 $\beta /$ IL-1 receptor type 1 axis during epileptogenesis provided neuroprotection (Noe et al., 2013). Our cytokine array shows an increase in a repertoire of cytokines and chemokines following epilepsy. This is consistent with a recent report that showed an upregulation of CCL2, CCL3, CCL5, and IL- $1 \beta$ in a pilocarpine model of epilepsy in rats (Arisi et al., 2015). It is important to note in our data that although there is an upregulation in endogenous IL-1 ra following epilepsy, it seems to be insufficient to counteract the large increase of both IL- $1 \alpha$ and IL- $1 \beta$ after epilepsy. How is IL- $1 \beta$ able to promote neuronal cell death after epilepsy? Several possibilities have been proposed in previous studies (Vezzani and Baram, 2007; Choi and Friedman, 2014). First, IL-1 $\beta$ is known to directly excite neurons via NMDA receptor activation (Vezzani et al., 1999). Not surprisingly, this increased neuronal excitability by IL- $1 \beta$ aggravates the neuronal hyperactivities and excitotoxicity that lead to severe hippocampal degeneration. Second, IL- $1 \beta$ is reported to regulate expression of the 75 neurotrophin receptor $\left(\mathrm{p} 75^{\mathrm{NTR}}\right)$ and induce neuronal cell death by activating the intrinsic caspase cascade (Troy et al., 2002). Third, IL-1 $\beta$ is able to 
directly trigger apoptosis signaling by activating NF-kB/NO and MAPK/caspase-3 signaling (Wang et al., 2005; Vetere et al., 2014). Collectively, our results suggested that CCL2-CCR2 signaling triggers STAT3 activation in microglia/macrophages, which in turn produces inflammatory cytokine IL-1 $\beta$ resulting in neuronal cell death after seizures.

We find that, in addition to being involved in seizure-induced neurodegeneration, CCL2-CCR2 signaling has a role in chronic seizure-related outcomes, such as anxiety, memory, and tolerance to secondary seizure episode. Evidence from previous studies revealed that CCR2-mediated trafficking of monocytes to the brain and activation of resident microglia promoted the establishment of anxiety-like behaviors (Wohleb et al., 2013; Sawada et al., 2014). Consistently, our results revealed reduced epilepsyinduced anxiety-like behavior in CCR $2^{-/-}$mice, in which both monocyte infiltration and microglial activation is suppressed. In line with our findings, another report showed that CCR2 deficiency prevented neuronal cognitive impairments induced by cranial irradiation (Belarbi et al., 2013). In these studies, CCR2mediated monocyte infiltration and their subsequent inflammatory repertoire were implicated in causing anxiety-like behavior and cognitive decline (Belarbi et al., 2013; Wohleb et al., 2013; Sawada et al., 2014). However, the exact mechanism underlying CCR2-mediated chronic seizure outcomes needs to be further investigated.

In conclusion, our current study revealed a novel CCL2CCR2 signaling cascade in hippocampal degeneration through STAT3 activation and IL- $1 \beta$ production after status epilepticus. Such information could contribute greatly to our understanding of this component of neuroinflammatory response, including microglial activation, macrophage recruitment, and production of proinflammatory mediators in causing epilepsy after a precipitating injury. Our study identifies CCL2-CCR2 signaling as a novel candidate target for future therapies to ameliorate neuroinflammatory damage following status epilepticus.

\section{References}

Akin D, Ravizza T, Maroso M, Carcak N, Eryigit T, Vanzulli I, Aker RG, Vezzani A, Onat FY (2011) IL-1beta is induced in reactive astrocytes in the somatosensory cortex of rats with genetic absence epilepsy at the onset of spike-and-wave discharges, and contributes to their occurrence. Neurobiol Dis 44:259-269. CrossRef Medline

Allan SM, Tyrrell PJ, Rothwell NJ (2005) Interleukin-1 and neuronal injury. Nat Rev Immunol 5:629-640. CrossRef Medline

Arisi GM, Foresti ML, Katki K, Shapiro LA (2015) Increased CCL2, CCL3, CCL5, and IL-1beta cytokine concentration in piriform cortex, hippocampus, and neocortex after pilocarpine-induced seizures. J Neuroinflammation 12:129. CrossRef Medline

Avignone E, Ulmann L, Levavasseur F, Rassendren F, Audinat E (2008) Status epilepticus induces a particular microglial activation state characterized by enhanced purinergic signaling. J Neurosci 28:9133-9144. CrossRef Medline

Beach TG, Woodhurst WB, MacDonald DB, Jones MW (1995) Reactive microglia in hippocampal sclerosis associated with human temporal lobe epilepsy. Neurosci Lett 191:27-30. CrossRef Medline

Belarbi K, Jopson T, Arellano C, Fike JR, Rosi S (2013) CCR2 deficiency prevents neuronal dysfunction and cognitive impairments induced by cranial irradiation. Cancer Res 73:1201-1210. CrossRef Medline

Boer K, Spliet WG, van Rijen PC, Redeker S, Troost D, Aronica E (2006) Evidence of activated microglia in focal cortical dysplasia. J Neuroimmunol 173:188-195. CrossRef Medline

Caplan R, Siddarth P, Stahl L, Lanphier E, Vona P, Gurbani S, Koh S, Sankar R, Shields WD (2008) Childhood absence epilepsy: behavioral, cognitive, and linguistic comorbidities. Epilepsia 49:1838-1846. CrossRef Medline

Cazareth J, Guyon A, Heurteaux C, Chabry J, Petit-Paitel A (2014) Molecular and cellular neuroinflammatory status of mouse brain after systemic lipopolysaccharide challenge: importance of CCR2/CCL2 signaling. J Neuroinflammation 11:132. CrossRef Medline

Cerri C, Genovesi S, Allegra M, Pistillo F, Püntener U, Guglielmotti A, Perry VH, Bozzi Y, Caleo M (2016) The chemokine CCL2 mediates the seizure-enhancing effects of systemic inflammation. J Neurosci 36:37773788. CrossRef Medline

Che X, Ye W, Panga L, Wu DC, Yang GY (2001) Monocyte chemoattractant protein-1 expressed in neurons and astrocytes during focal ischemia in mice. Brain Res 902:171-177. CrossRef Medline

Chen W, Gao Q, Han S, Pan F, Fan W (2015) The CCL2/CCR2 axis enhances IL-6-induced epithelial-mesenchymal transition by cooperatively activating STAT3-Twist signaling. Tumour Biol 36:973-981. CrossRef Medline

Chen Y, Hallenbeck JM, Ruetzler C, Bol D, Thomas K, Berman NE, Vogel SN (2003) Overexpression of monocyte chemoattractant protein 1 in the brain exacerbates ischemic brain injury and is associated with recruitment of inflammatory cells. J Cereb Blood Flow Metab 23:748-755. CrossRef Medline

Choi J, Nordli DR Jr, Alden TD, DiPatri A Jr, Laux L, Kelley K, Rosenow J, Schuele SU, Rajaram V, Koh S (2009) Cellular injury and neuroinflammation in children with chronic intractable epilepsy. J Neuroinflammation 6:38. CrossRef Medline

Choi S, Friedman WJ (2014) Interleukin-1beta enhances neuronal vulnerability to proNGF-mediated apoptosis by increasing surface expression of p75(NTR) and sortillin. Neuroscience 257:11-19. CrossRef Medline

Dedeurwaerdere S, Friedman A, Fabene PF, Mazarati A, Murashima YL, Vezzani A, Baram TZ (2012) Finding a better drug for epilepsy: antiinflammatory targets. Epilepsia 53:1113-1118. CrossRef Medline

Devinsky O, Vezzani A, Najjar S, De Lanerolle NC, Rogawski MA (2013) Glia and epilepsy: excitability and inflammation. Trends Neurosci 36: 174-184. CrossRef Medline

Ding Z, Mathur V, Ho PP, James ML, Lucin KM, Hoehne A, Alabsi H, Gambhir SS, Steinman L, Luo J, Wyss-Coray T (2014) Antiviral drug ganciclovir is a potent inhibitor of microglial proliferation and neuroinflammation. J Exp Med 211:189-198. CrossRef Medline

Drexel M, Preidt AP, Sperk G (2012) Sequel of spontaneous seizures after kainic acid-induced status epilepticus and associated neuropathological changes in the subiculum and entorhinal cortex. Neuropharmacology 63:806-817. CrossRef Medline

Eyo UB, Wu LJ (2013) Bi-directional microglia-neuron communication in the healthy brain. Neural Plast 2013:456857. CrossRef Medline

Eyo UB, Peng J, Swiatkowski P, Mukherjee A, Bispo A, Wu LJ (2014) Neuronal hyperactivity recruits microglial processes via neuronal NMDA receptors and microglial P2Y12 receptors after status epilepticus. J Neurosci 34:10528-10540. CrossRef Medline

Eyo UB, Gu N, De S, Dong H, Richardson JR, Wu LJ (2015) Modulation of microglial process convergence toward neuronal dendrites by extracellular calcium. J Neurosci 35:2417-2422. CrossRef Medline

Eyo UB, Peng J, Murugan M, Mo M, Lalani A, Xie P, Xu P, Margolis DJ, Wu LJ (2016) Regulation of physical microglia-neuron interactions by fractalkine signaling after status epilepticus. eNeuro 3:pii:ENEURO.0209_ 16.2016. CrossRef Medline

Eyo UB, Murugan M, Wu LJ (2017) Microglia-neuron communication in epilepsy. Glia 65:5-18. CrossRef Medline

Fisher RS, van Emde Boas W, Blume W, Elger C, Genton P, Lee P, Engel J Jr (2005) Epileptic seizures and epilepsy: definitions proposed by the International League Against Epilepsy (ILAE) and the International Bureau for Epilepsy (IBE). Epilepsia 46:470-472. CrossRef Medline

Foresti ML, Arisi GM, Katki K, Montañez A, Sanchez RM, Shapiro LA (2009) Chemokine CCL2 and its receptor CCR2 are increased in the hippocampus following pilocarpine-induced status epilepticus. J Neuroinflammation 6:40. CrossRef Medline

Fukuda M, Hino H, Suzuki Y, Takahashi H, Morimoto T, Ishii E (2014) Postnatal interleukin-1beta enhances adulthood seizure susceptibility and neuronal cell death after prolonged experimental febrile seizures in infantile rats. Acta Neurol Belg 114:179-185. CrossRef Medline

Gaitatzis A, Johnson AL, Chadwick DW, Shorvon SD, Sander JW (2004) Life expectancy in people with newly diagnosed epilepsy. Brain 127:24272432. CrossRef Medline

Grabenstatter HL, Del Angel YC, Carlsen J, Wempe MF, White AM, Cogswell M, Russek SJ, Brooks-Kayal AR (2014) The effect of STAT3 inhibition on status epilepticus and subsequent spontaneous seizures in the pilo- 
carpine model of acquired epilepsy. Neurobiol Dis 62:73-85. CrossRef Medline

Huang DR, Wang J, Kivisakk P, Rollins BJ, Ransohoff RM (2001) Absence of monocyte chemoattractant protein 1 in mice leads to decreased local macrophage recruitment and antigen-specific $\mathrm{T}$ helper cell type $1 \mathrm{im}-$ mune response in experimental autoimmune encephalomyelitis. J Exp Med 193:713-726. CrossRef Medline

Hughes PM, Allegrini PR, Rudin M, Perry VH, Mir AK, Wiessner C (2002) Monocyte chemoattractant protein-1 deficiency is protective in a murine stroke model. J Cereb Blood Flow Metab 22:308-317. CrossRef Medline

Hung YW, Lai MT, Tseng YJ, Chou CC, Lin YY (2013) Monocyte chemoattractant protein- 1 affects migration of hippocampal neural progenitors following status epilepticus in rats. J Neuroinflammation 10:11. CrossRef Medline

Izumi K, Fang LY, Mizokami A, Namiki M, Li L, Lin WJ, Chang C (2013) Targeting the androgen receptor with siRNA promotes prostate cancer metastasis through enhanced macrophage recruitment via CCL2/CCR2induced STAT3 activation. EMBO Mol Med 5:1383-1401. CrossRef Medline

Janigro D, Iffland PH 2nd, Marchi N, Granata T (2013) A role for inflammation in status epilepticus is revealed by a review of current therapeutic approaches. Epilepsia 54 [Suppl 6]:30-32. CrossRef Medline

Kalehua AN, Nagel JE, Whelchel LM, Gides JJ, Pyle RS, Smith RJ, Kusiak JW, Taub DD (2004) Monocyte chemoattractant protein-1 and macrophage inflammatory protein-2 are involved in both excitotoxin-induced neurodegeneration and regeneration. Exp Cell Res 297:197-211. CrossRef Medline

Kitazawa M, Cheng D, Tsukamoto MR, Koike MA, Wes PD, Vasilevko V, Cribbs DH, LaFerla FM (2011) Blocking IL-1 signaling rescues cognition, attenuates tau pathology, and restores neuronal beta-catenin pathway function in an Alzheimer's disease model. J Immunol 187: 6539-6549. CrossRef Medline

Koprich JB, Reske-Nielsen C, Mithal P, Isacson O (2008) Neuroinflammation mediated by IL-1beta increases susceptibility of dopamine neurons to degeneration in an animal model of Parkinson's disease. J Neuroinflammation 5:8. CrossRef Medline

Lee HK, Choi SS, Han KJ, Han EJ, Suh HW (2003) Cycloheximide inhibits neurotoxic responses induced by kainic acid in mice. Brain Res Bull 61: 99-107. CrossRef Medline

Leung SY, Wong MP, Chung LP, Chan AS, Yuen ST (1997) Monocyte chemoattractant protein-1 expression and macrophage infiltration in gliomas. Acta Neuropathol 93:518-527. CrossRef Medline

Lin TH, Izumi K, Lee SO, Lin WJ, Yeh S, Chang C (2013) Anti-androgen receptor ASC-J9 versus anti-androgens MDV3100 (Enzalutamide) or Casodex (Bicalutamide) leads to opposite effects on prostate cancer metastasis via differential modulation of macrophage infiltration and STAT3-CCL2 signaling. Cell Death Dis 4:e764. CrossRef Medline

Manley NC, Bertrand AA, Kinney KS, Hing TC, Sapolsky RM (2007) Characterization of monocyte chemoattractant protein-1 expression following a kainate model of status epilepticus. Brain Res 1182:138-143. CrossRef Medline

Marchi N, Granata T, Ghosh C, Janigro D (2012) Blood-brain barrier dysfunction and epilepsy: pathophysiologic role and therapeutic approaches. Epilepsia 53:1877-1886. CrossRef Medline

Marchi N, Granata T, Janigro D (2014) Inflammatory pathways of seizure disorders. Trends Neurosci 37:55-65. CrossRef Medline

Matsuda T, Murao N, Katano Y, Juliandi B, Kohyama J, Akira S, Kawai T, Nakashima K (2015) TLR9 signalling in microglia attenuates seizureinduced aberrant neurogenesis in the adult hippocampus. Nat Commun 6:6514. CrossRef Medline

Mirrione MM, Konomos DK, Gravanis I, Dewey SL, Aguzzi A, Heppner FL, Tsirka SE (2010) Microglial ablation and lipopolysaccharide preconditioning affects pilocarpine-induced seizures in mice. Neurobiol Dis 39: 85-97. CrossRef Medline

Miskin C, Hasbani DM (2014) Status epilepticus: immunologic and inflammatory mechanisms. Semin Pediatr Neurol 21:221-225. CrossRef Medline

Noe FM, Polascheck N, Frigerio F, Bankstahl M, Ravizza T, Marchini S, Beltrame L, Bandero CR, Löscher W, Vezzani A (2013) Pharmacological blockade of IL-1beta/IL-1 receptor type 1 axis during epileptogenesis provides neuroprotection in two rat models of temporal lobe epilepsy. Neurobiol Dis 59:183-193. CrossRef Medline

Patel HC, Ross FM, Heenan LE, Davies RE, Rothwell NJ, Allan SM (2006)
Neurodegenerative actions of interleukin- 1 in the rat brain are mediated through increases in seizure activity. J Neurosci Res 83:385-391. CrossRef Medline

Przanowski P, Dabrowski M, Ellert-Miklaszewska A, Kloss M, Mieczkowski J, Kaza B, Ronowicz A, Hu F, Piotrowski A, Kettenmann H, Komorowski J, Kaminska B (2014) The signal transducers Stat1 and Stat3 and their novel target Jmjd3 drive the expression of inflammatory genes in microglia. J Mol Med (Berl) 92:239-254. CrossRef Medline

Qin H, Yeh WI, De Sarno P, Holdbrooks AT, Liu Y, Muldowney MT, Reynolds SL, Yanagisawa LL, Fox TH 3rd, Park K, Harrington LE, Raman C, Benveniste EN (2012) Signal transducer and activator of transcription3/suppressor of cytokine signaling-3 (STAT3/SOCS3) axis in myeloid cells regulates neuroinflammation. Proc Natl Acad Sci U S A 109:50045009. CrossRef Medline

Racine RJ (1972) Modification of seizure activity by electrical stimulation. II. Motor seizure. Electroencephalogr Clin Neurophysiol 32:281-294. CrossRef Medline

Rogove AD, Tsirka SE (1998) Neurotoxic responses by microglia elicited by excitotoxic injury in the mouse hippocampus. Curr Biol 8:19-25. CrossRef Medline

Rollins BJ (1991) JE/MCP-1: an early-response gene encodes a monocytespecific cytokine. Cancer Cells 3:517-524. Medline

Sawada A, Niiyama Y, Ataka K, Nagaishi K, Yamakage M, Fujimiya M (2014) Suppression of bone marrow-derived microglia in the amygdala improves anxiety-like behavior induced by chronic partial sciatic nerve ligation in mice. Pain 155:1762-1772. CrossRef Medline

Schauwecker PE (2012) Strain differences in seizure-induced cell death following pilocarpine-induced status epilepticus. Neurobiol Dis 45:297304. CrossRef Medline

Selenica ML, Alvarez JA, Nash KR, Lee DC, Cao C, Lin X, Reid P, Mouton PR, Morgan D, Gordon MN (2013) Diverse activation of microglia by chemokine (C-C motif) ligand 2 overexpression in brain. J Neuroinflammation 10:86. CrossRef Medline

Semple BD, Kossmann T, Morganti-Kossmann MC (2010) Role of chemokines in CNS health and pathology: a focus on the CCL2/CCR2 and CXCL8/CXCR2 networks. J Cereb Blood Flow Metab 30:459-473. CrossRef Medline

Severini C, Passeri PP, Ciotti M, Florenzano F, Possenti R, Zona C, Di Matteo A, Guglielmotti A, Calissano P, Pachter J, Mercanti D (2014) Bindarit, inhibitor of CCL2 synthesis, protects neurons against amyloid-betainduced toxicity. J Alzheimers Dis 38:281-293. CrossRef Medline

Shapiro LA, Wang L, Ribak CE (2008) Rapid astrocyte and microglial activation following pilocarpine-induced seizures in rats. Epilepsia 49 [Suppl 2]:33-41. CrossRef Medline

Sheehan JJ, Zhou C, Gravanis I, Rogove AD, Wu YP, Bogenhagen DF, Tsirka SE (2007) Proteolytic activation of monocyte chemoattractant protein-1 by plasmin underlies excitotoxic neurodegeneration in mice. J Neurosci 27: 1738-1745. CrossRef Medline

Shi C, Pamer EG (2011) Monocyte recruitment during infection and inflammation. Nat Rev Immunol 11:762-774. CrossRef Medline

Temkin NR (2009) Preventing and treating posttraumatic seizures: the human experience. Epilepsia 50 [Suppl 2]:10-13. CrossRef Medline

Thom M (2014) Review: hippocampal sclerosis in epilepsy: a neuropathology review. Neuropathol Appl Neurobiol 40:520-543. CrossRef Medline

Thurman DJ, Beghi E, Berg AT, Buchhalter JR, Ding D, Hesdorffer DC, Hauser WA, Kazis L, Kobau R, Kroner B, Labiner D, Liow K, Logroscino G, Medina MT, Newton CR, Parko K, Paschal A, Preux PM, Sander JW, Selassie A, et al. (2011) Standards for epidemiologic studies and surveillance of epilepsy. Epilepsia 52 [Suppl 7]:2-26. CrossRef Medline

Troy CM, Friedman JE, Friedman WJ (2002) Mechanisms of p75-mediated death of hippocampal neurons. Role of caspases. J Biol Chem 277:3429534302. CrossRef Medline

Vetere A, Choudhary A, Burns SM, Wagner BK (2014) Targeting the pancreatic beta-cell to treat diabetes. Nat Rev Drug Discov 13:278-289. CrossRef Medline

Vezzani A, Baram TZ (2007) New roles for interleukin-1 Beta in the mechanisms of epilepsy. Epilepsy Curr 7:45-50. CrossRef Medline

Vezzani A, Viviani B (2015) Neuromodulatory properties of inflammatory cytokines and their impact on neuronal excitability. Neuropharmacology 96:70-82. CrossRef Medline

Vezzani A, Conti M, De Luigi A, Ravizza T, Moneta D, Marchesi F, De Simoni MG (1999) Interleukin- $1 \beta$ immunoreactivity and microglia are en- 
hanced in the rat hippocampus by focal kainate application: functional evidence for enhancement of electrographic seizures. J Neurosci 19:50545065. Medline

Vezzani A, French J, Bartfai T, Baram TZ (2011) The role of inflammation in epilepsy. Nat Rev Neurol 7:31-40. CrossRef Medline

Wang DD, Englot DJ, Garcia PA, Lawton MT, Young WL (2012) Minocyclineand tetracycline-class antibiotics are protective against partial seizures in vivo. Epilepsy Behav 24:314-318. CrossRef Medline

Wang XJ, Kong KM, Qi WL, Ye WL, Song PS (2005) Interleukin-1 beta induction of neuron apoptosis depends on $\mathrm{p} 38$ mitogen-activated protein kinase activity after spinal cord injury. Acta Pharmacol Sin 26:934-942. CrossRef Medline

Wen Z, Zhong Z, Darnell JE Jr (1995) Maximal activation of transcription by Stat 1 and Stat 3 requires both tyrosine and serine phosphorylation. Cell 82:241-250. CrossRef Medline

Wohleb ES, Powell ND, Godbout JP, Sheridan JF (2013) Stress-induced recruitment of bone marrow-derived monocytes to the brain promotes anxiety-like behavior. J Neurosci 33:13820-13833. CrossRef Medline
Wu LJ, Wu G, Akhavan Sharif MR, Baker A, Jia Y, Fahey FH, Luo HR, Feener EP, Clapham DE (2012) The voltage-gated proton channel Hv1 enhances brain damage from ischemic stroke. Nat Neurosci 15:565-573. CrossRef Medline

Wu Y, Wang X, Mo X, Xi Z, Xiao F, Li J, Zhu X, Luan G, Wang Y, Li Y, Zhang J (2008) Expression of monocyte chemoattractant protein-1 in brain tissue of patients with intractable epilepsy. Clin Neuropathol 27:55-63. CrossRef Medline

Yamasaki R, Lu H, Butovsky O, Ohno N, Rietsch AM, Cialic R, Wu PM, Doykan CE, Lin J, Cotleur AC, Kidd G, Zorlu MM, Sun N, Hu W, Liu L, Lee JC, Taylor SE, Uehlein L, Dixon D, Gu J, et al. (2014) Differential roles of microglia and monocytes in the inflamed central nervous system. J Exp Med 211:1533-1549. CrossRef Medline

Zhang Y, Chen K, Sloan SA, Bennett ML, Scholze AR, O'Keeffe S, Phatnani HP, Guarnieri P, Caneda C, Ruderisch N, Deng S, Liddelow SA, Zhang C, Daneman R, Maniatis T, Barres BA, Wu JQ (2014) An RNA-sequencing transcriptome and splicing database of glia, neurons, and vascular cells of the cerebral cortex. J Neurosci 34:11929-11947. CrossRef Medline 